\title{
molecules
}

ISSN 1420-3049

www.mdpi.com/journal/molecules

Article

\section{Studies on Cytotoxic Activity against HepG-2 Cells of Naphthoquinones from Green Walnut Husks of Juglans mandshurica Maxim}

\section{Yuanyuan Zhou ${ }^{1, \dagger}$, Bingyou Yang ${ }^{1, \dagger}$, Yanqiu Jiang ${ }^{1}$, Zhaoxi Liu ${ }^{1}$, Yuxin Liu ${ }^{1}$, Xiaoli Wang ${ }^{2}$ and Haixue Kuang 1,*}

1 College of Pharmacy, Heilongjiang University of Chinese Medicine, Harbin 150040, China; E-Mails: zhouyuanyuan1998@163.com(Y.Z.); ybywater@163.com (B.Y.); jiangyanqiu219@163.com (Y.J.); liu_zhao_xi@163.com (Z.L.); ZYC19901014@126.com (Y.L.)

2 College of Adult Education, Heilongjiang University of Chinese Medicine, Harbin 150040, China; E-Mail: wangxiaolicando2000@126.com

$\dagger$ These authors contributed equally to this work.

* Author to whom correspondence should be addressed; E-Mail: hxkuang@hotmail.com; Tel.: +86-451-8219-3001; Fax: +86-451-8211-0803.

Academic Editor: Isabel C. F. R. Ferreira

Received: 20 July 2015 / Accepted: 19 August 2015 / Published: 26 August 2015

\begin{abstract}
Twenty-seven naphthoquinones and their derivatives, including four new naphthalenyl glucosides and twenty-three known compounds, were isolated from green walnut husks, which came from Juglans mandshurica Maxim. The structures of four new naphthalenyl glucosides were elucidated based on extensive spectroscopic analyses. All of these compounds were evaluated for their cytotoxic activities against the growth of human cancer cells lines HepG-2 by MTT [3-(4,5-dimethylthiazo 1-2-yl)-2,5 diphenyl tetrazolium bromide] assay. The results were shown that most naphthoquinones in an aglycone form exhibited better cytotoxicity in vitro than naphthalenyl glucosides with $\mathrm{IC}_{50}$ values in the range of $7.33-88.23 \mu \mathrm{M}$. Meanwhile, preliminary structure-activity relationships for these compounds were discussed.
\end{abstract}

Keywords: Juglans mandshurica Maxim; green walnut husks; naphthoquinones; cytotoxic activity; structure-activity relationships 


\section{Introduction}

With the increased use of natural product-based cancer chemotherapy, exploring the cytotoxic activity of phytochemicals for anticancer drug design has gained extensive attention worldwide [1]. Juglans mandshurica Maxim is a well-known member of the Juglandaceae family which is widely distributed throughout urban and rural areas in northeast China [2-4]. A few distrubute in Russia, Korea and Japan. It is one of the most important medical plants of which the green husks, leaf, root and bark all can be medically used [5-8]. Its green husks have been used as a folk medicine for treatment of gastric ulcers, uterine prolapse, leukopenia, diarrhea and dysentery for many years in China [9]. In recent years, many studies showed that green walnut husks have obvious advantages in tumor treatment like liver cancer [9-11].

Based on our interest in natural antitumor sources prompted us to continue investigating the phytochemicals and cytotoxicity of this plant [12-16]. A number of extracts and compounds obtained from medical materials have been identified as in vitro tumor inhibitors [7,9]. These beneficial effects have largely been ascribed to the presence of naphthoquinones. Naphthoquinones are the most important and widely distributed chemical class in the quinone family. Their derivatives have exhibited a variety of biological responses which include antiallergic, antibacterial, antifungal, anti-inflammatory, antithrombotic, antiplatelet, antiviral, apoptosis, lipoxygenase, radical scavenging, and anti-ringworm activities. Many studies have shown that naphthoquinones have biological activities specifically against pathogenic protozoa and cancer cells owing to their privileged structures in medicinal chemistry [17]. In this study, we obtained a series of naphthoquinone aglycones and glucosides, and then presented the isolation and structural elucidation of four new naphthalenyl glucosides (compounds 18, 25-27), together with 23 known compounds from green walnut husks of J. mandshurica Maxim. These included juglone (1), 5-methoxy-1,4-naphthoquinone (2), 5,8-dihydroxy-1,4-naphthoquinone (3), 2-hydroxy-1,4-naphthoquinone (4), 2,5-dihydroxy-1,4-naphthoquinone (5), 3,5-dihydroxy-1,4-naphthoquinone (6), 3-methoxy juglone (7), 2-methoxy juglone (8), 3-ethoxy juglone (9), 2-ethoxy juglone (10), Engelharquinone (11), $(S)$-regiolone (12), (4S)-4-hydroxy- $\alpha$-tetralone (13), (4S)-5-hydroxy-4-methoxy- $\alpha$-tetralone (14), 1,4,5trihydroxynaphthalene-1,4-di- $O$ - $\beta$-D-glucopyrano side (15), 1,4,5-trihydroxynaphthalene-1,5-di- $O$ - $\beta$ D-glucopyranoside (16), 1,4,8-trihydroxynaphthalene-1-O- $\beta$-D-glucopyranoside (17), 1,4,8-trihydroxy3-naphthalenecarboxylic acid -1-O- $\beta$-D-glucopyranoside ethyl ester (18), 1,4,8-trihydroxynaphthalene1-O- $\beta$-D-[6'-O-(3",4",5"-trihydroxybenzoyl)]glucopyranoside (19), (4S)-4-hydroxy- $\alpha$-tetralone-4-O- $\beta$ D-glucopyranoside (20), (4S)-4,5-dihydroxy- $\alpha$-tetralone 4-O- $\beta$-D-glucopyranoside (21), (4S)-4,6-dihydroxy$\alpha$-tetralone 4- $O$ - $\beta$-D-glucopyranoside (22), (4S)-4,5,8-trihydroxy- $\alpha$-tetralone $4-O$ - $\beta$-D-glucopyranoside (23), (4S)-4,5,8-trihydroxy- $\alpha$-tetralone 5-O- $\beta$-D-[6'-O-(3",4",5"-trihydroxybenzoyl)] glucopyranoside (24), (4S)-4-hydroxy- $\alpha$-tetralone-4-O- $\beta$-D-(6'-O-4"'-hydroxylbenzoyl)glucopyranoside (25), (4S)-4,5-dihydroxy$\alpha$-tetralone-4- $O-\beta$-D-(6'-O-4"'-hydroxylbenzoyl)glucopyranoside (26), (4S)-4,5,8-thihydroxy- $\alpha$-tetralone$5-O-\beta$-D-(6'-O-4"-hydroxylbenzoyl)glucopyranoside (27). In this study, we explored the antitumor structure-activity relationships using above compounds against the growth of liver cancer cell HepG-2 by MTT assays. The aim of this work was to define the key naphthoquinone structural elements that were required for cytotoxic activity through the determination of the ability of 27 naphthoquinones belonging to main structural subtypes such as naphthoquinone, tetralone, and naphthols. 


\section{Results and Discussion}

\subsection{Isolation and Characterization of Compounds 18, 25-27}

The compounds were isolated using silica gel columns and semi-preparative HPLC chromatography from 30\% ethanol extract of fresh green husks of Juglans mandshurica Maxim. The structures of four new naphthalenyl glucosides were elucidated based on extensive mass and spectroscopic analyses including HR-ESI-MS, IR, ${ }^{1} \mathrm{H}-\mathrm{NMR},{ }^{13} \mathrm{C}-\mathrm{NMR}$, DEPT, HSQC, HMBC, and CD. Their structures, ${ }^{1} \mathrm{H}$ - and ${ }^{13} \mathrm{C}-\mathrm{NMR}$ data, and HMBC correlations are shown in Figures 1 and 2 and Table 1.
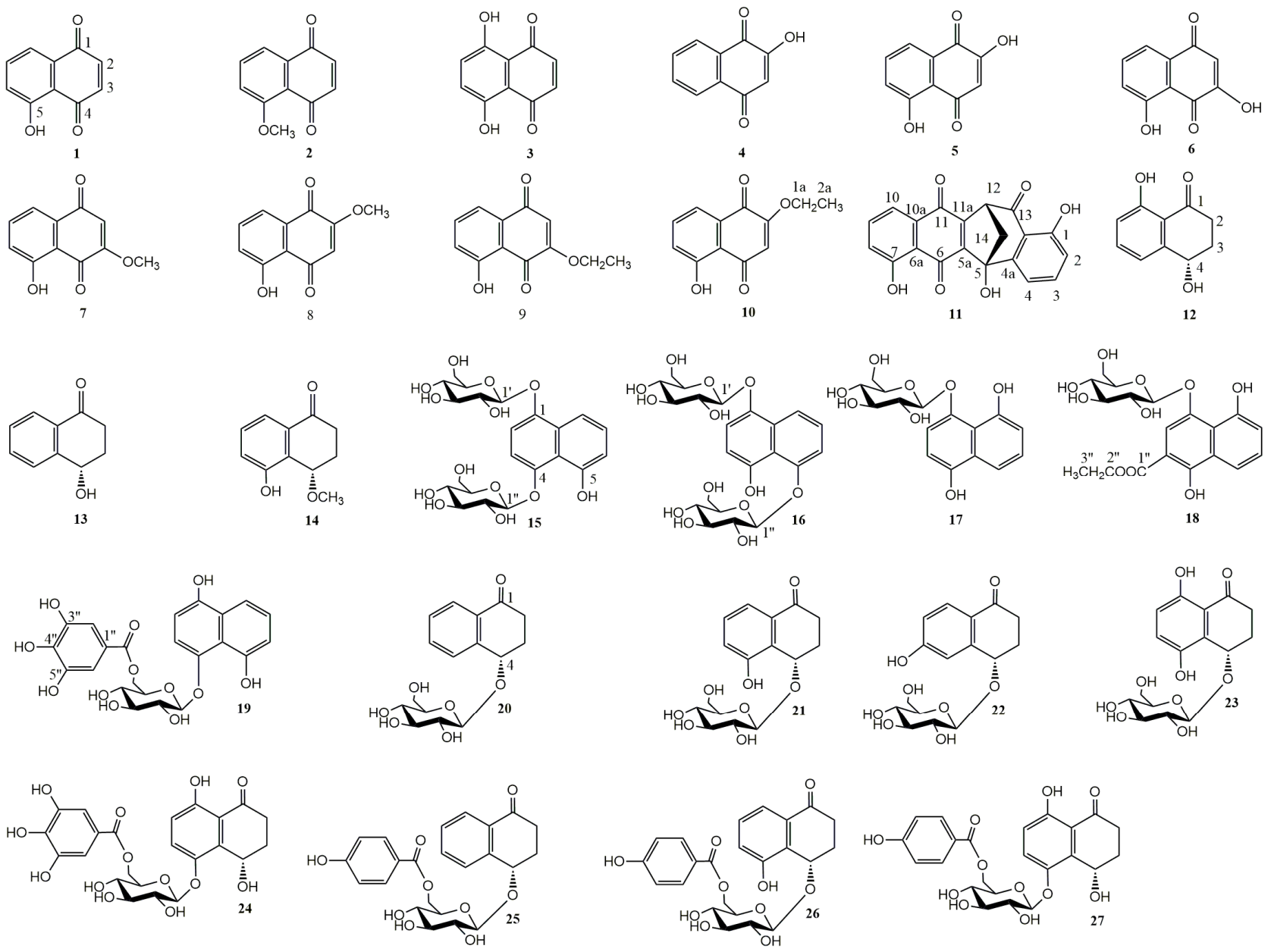

Figure 1. The chemical structures of compounds 1-27.

Compound 18 was a red amorphous powder. The molecular formula $\mathrm{C}_{19} \mathrm{H}_{22} \mathrm{O}_{10}$ was determined from HR-ESI-MS and ${ }^{13} \mathrm{C}-\mathrm{NMR}$ data. There were two major differences between 18 and 25-27: two methylene groups located at C-2 and C-3, respectively, at $\delta_{C}$ 33.0-35.0 and 30.0-31.5 in compounds 25-27 were replaced by methenyl groups at $\delta_{\mathrm{C}} 109.9$ and 105.8 in compound $\mathbf{1 8}$, indicating no presence of a hydrogenated position. Furthermore, the independent existence of the glucopyranosyl moiety was not together with $p$-hydroxybenzoly on the basis of 1D-, 2D-NMR data. Noise-decoupled ${ }^{13} \mathrm{C}-\mathrm{NMR}$ and the distortionless enhancement by polarization transfer (DEPT) spectrum of $\mathbf{1 8}$ showed 19 carbon peaks, including one methyl, two methylenes, nine methynes, and seven quaternary carbons. There were 10 carbons due to the naphthalene ring, six carbons due to the glucose, and a carbonyl ketone at 
$\delta_{\mathrm{C}} 171.8$ correlated with one ethyl group, which was assigned to acetyl group. In the ${ }^{1} \mathrm{H}-\mathrm{NMR}$ spectrum, there were ABC-spin aromatic proton signals at $\delta_{\mathrm{H}} 6.99$ (dd, $\left.J=1.0,7.8 \mathrm{~Hz}, \mathrm{H}-5\right), 7.40(\mathrm{t}, J=7.8 \mathrm{~Hz}$, $\mathrm{H}-6$ ), and 7.86 (dd, $J=1.0,7.8 \mathrm{~Hz}, \mathrm{H}-7$ ), which couple among themselves. Moreover, one isolated proton signal due to $\mathrm{H}-2$ at $\delta_{\mathrm{H}} 7.72$ and one double-peak signal due to an anomeric proton at $\delta_{\mathrm{H}} 4.99$ were distinct. In the HMBC spectrum of 18 (Figure 2), the correlation peak between the anomeric proton and $\mathrm{C}-1$ at $\delta_{\mathrm{C}} 148.0$ was observed. The results implied that the glucopyranosyl was linked to $\mathrm{C}-1$ of the aglycone (Table 1, Figure 2). Thus, the structure of $\mathbf{1 8}$ was elucidated as 1,4,8-trihydroxy-3naphthalenecarboxylic acid 1-O- $\beta$-D-glucopyranoside ethyl ester.

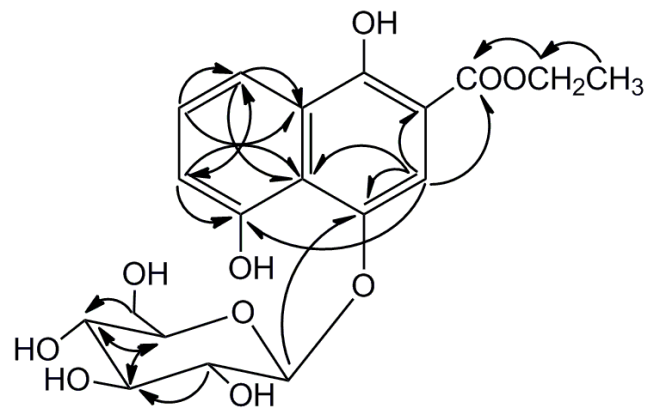

18

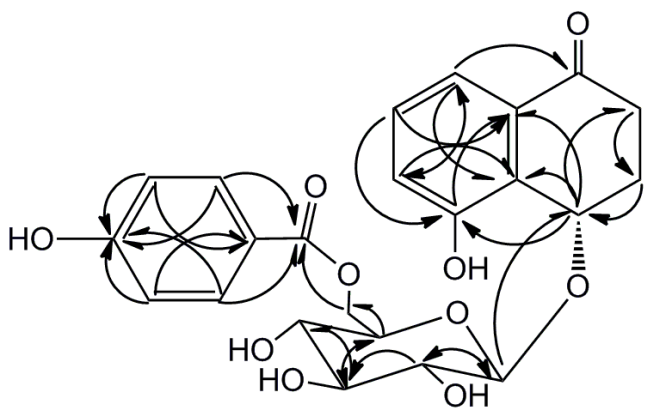

26

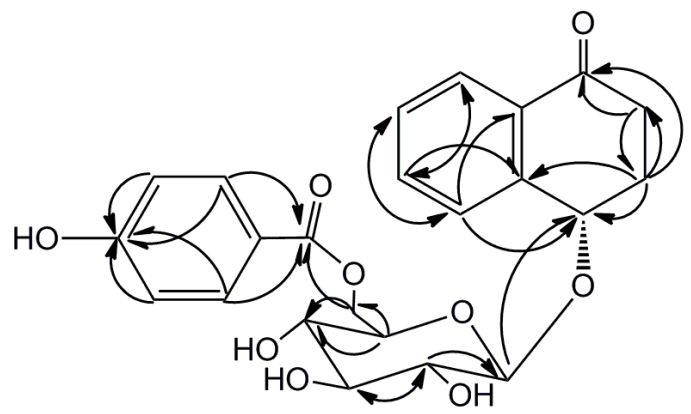

25

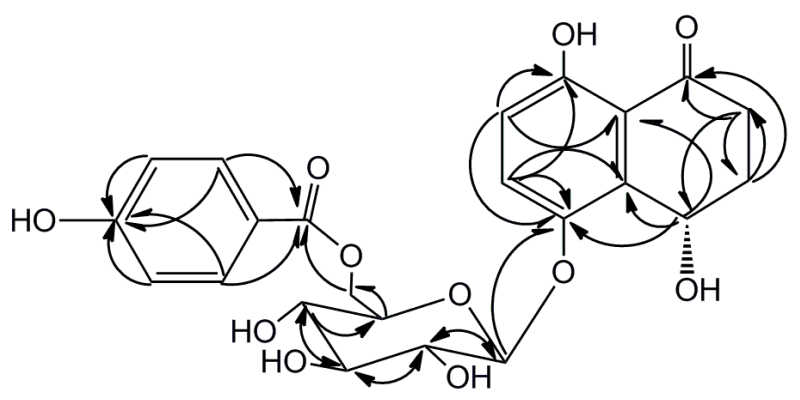

27

Figure 2. Key HMBC correlations of compounds 18, 25-27.

Compound 25 was obtained as a yellow amorphous powder and the molecular formula was assigned as $\mathrm{C}_{23} \mathrm{H}_{24} \mathrm{O}_{9}$ from its HR-ESI-MS and ${ }^{13} \mathrm{C}-\mathrm{NMR}$ data. ${ }^{1} \mathrm{H}-\mathrm{NMR}$ and ${ }^{13} \mathrm{C}-\mathrm{NMR}$ spectra revealed that 25 contained a typical $\beta$-D-glucopyranosyl $\left(\delta_{\mathrm{H}} 4.42\left(\mathrm{~d}, J=7.6 \mathrm{~Hz}, \mathrm{H}-1^{\prime}\right) ; \delta_{\mathrm{C}} 103.7,75.2,78.1,72.2,75.5\right.$, 65.0), which was confirmed by acid hydrolysis and co-chromatography in comparison with an authentic sample. Moreover, the remaining 17 carbon signals, which respectively belong to the tetralone moiety and a $p$-hydroxybenzoly group, were attributable to two methylenes, nine methines, four olefinic quaternary carbons, and two quaternary carbonyl groups. To ascertain the structure of the aglycone and the glycosidic connection, a complete ${ }^{1} \mathrm{H}$ - and ${ }^{13} \mathrm{C}$-NMR spectral assignment was carried out utilizing a combination of DEPT, HSQC, HMBC, and CD experiments. To be specific, the ${ }^{1} \mathrm{H}-\mathrm{NMR}$ spectrum of 25 showed two methylenes of tetralone at $\delta_{\mathrm{H}} 2.87$ (ddd, $\left.J=4.5,8.9,17.5 \mathrm{~Hz}, \mathrm{H}_{\mathrm{ax}}-2\right)$ and $\delta_{\mathrm{H}} 2.41$ (ddd, $\left.J=4.5,6.5,17.5 \mathrm{~Hz}, \mathrm{H}_{\mathrm{eq}}-2\right)$; 2.34 (dddd, $J=2.2,4.5,8.9,13.4 \mathrm{~Hz}, \mathrm{H}_{\mathrm{ax}}-3$ ) and 2.28 (dddd, $J=3.8,4.5$, $\left.6.5,13.4 \mathrm{~Hz}, \mathrm{Heq}_{\mathrm{e}}-3\right)$, corresponding to $\mathrm{C}$-atom signals at $\delta_{\mathrm{C}} 35.5$ and 31.5 in the HSQC spectrum. In the ${ }^{1} \mathrm{H}-\mathrm{NMR}$ spectrum, there was a set of correlation signals at $\delta_{\mathrm{H}} 7.65$ (br.d, $J=7.6 \mathrm{~Hz}, \mathrm{H}-5$ ), 7.52 (dt, $J=1.2,7.6 \mathrm{~Hz}, \mathrm{H}-6$ ), 7.43 (dt, $J=1.2,7.6 \mathrm{~Hz}, \mathrm{H}-7$ ), and 7.93 (dd, $J=1.2,7.6 \mathrm{~Hz}, \mathrm{H}-8$ ) due to an 
ortho-disubstituted aromatic ring. All above data implied that 25 was an $\alpha$-tetralone derivative. Hydrolysis of $\mathbf{2 5}$ yielded glucose, which was identified on a thin layer chromatography (TLC) plate by comparison with a reference sample. Moreover, a suggestive correlation was observed between the anomeric proton signal of glucose and a methane carbon signal at $\delta \mathrm{C} 75.9(\mathrm{C}-4)$ in the HMBC spectrum (Figure 2), indicating that the sugar moiety was linked at the $\mathrm{C}-4$ position. The $\beta$-anomeric configuration for glucopyranose was determined from the $J_{\mathrm{H} 1, \mathrm{H} 2}$ value $(7.6 \mathrm{~Hz})$. At the same time, it was also observed that the $\delta_{\mathrm{H}} 4.66$ (dd, $\left.J=2.2,11.8 \mathrm{~Hz}, \mathrm{H}-6^{\prime} \mathrm{a}\right)$ and 4.47 (dd, $\left.J=7.2 \mathrm{~Hz}, 11.8 \mathrm{~Hz}, \mathrm{H}-6{ }^{\prime} \mathrm{b}\right)$ had a linkage with formyl group. There were two sets of high peaks at $\delta \mathrm{H} 7.95$ (d, $\left.J=8.8 \mathrm{~Hz}, \mathrm{H}-2^{\prime \prime}, 6^{\prime \prime}\right), 6.84(\mathrm{~d}$, $\left.J=8.8 \mathrm{~Hz}, \mathrm{H}-3^{\prime \prime}, 5^{\prime \prime}\right)$, and $\delta_{\mathrm{C}} 132.9\left(\mathrm{C}-2^{\prime \prime}, 6^{\prime \prime}\right), 116.3\left(\mathrm{C}-3^{\prime \prime}, 5^{\prime \prime}\right)$ in the ${ }^{1} \mathrm{H}-$ and ${ }^{13} \mathrm{C}-\mathrm{NMR}$ spectrum, indicating the presence of $p$-hydroxybenzoly. To determine the absolute configuration of the chiral center at the C-4 position, 25 was hydrolyzed to give the aglycone, which was identified to be $S$ configuration by comparing its NMR data with those of the reference $[18,19]$ and the circular dichrosim CD spectrum, where a negative Cotton effect at $236 \mathrm{~nm}$ was observed. On the basis of the above evidence, the structure of 25 was established as (4S)-4-hydroxy- $\alpha$-tetralone 4-O- $\beta$-D-(6'-O-4"-hydroxybenzoyl) glucopyranoside.

Compound 26, a yellow amorphous powder, was assigned as $\mathrm{C}_{23} \mathrm{H}_{24} \mathrm{O}_{10}$ on the basis of its HR-ESI-MS and ${ }^{13} \mathrm{C}-\mathrm{NMR}$ data. The 1D- and 2D-NMR spectrographic data were similar as compound $\mathbf{2 5}$ except for the aryl ring moiety of the tetralone. The ${ }^{1} \mathrm{H}-\mathrm{NMR}$ spectrum of $\mathbf{2 6}$ showed a set of proton signals that was in accordance with the ABC-type aromatic proton signals, indicating the presence of a hydroxyl group at the $\mathrm{C}-5$ position on the aromatic ring. The position of the hydroxyl group was also deduced to the $\mathrm{C}-5$ position by observation of the correlations between $\delta_{\mathrm{H}} 5.37(\mathrm{H}-4)$ and $\delta_{\mathrm{C}} 157.0(\mathrm{C}-5)$ in the HMBC spectrum (Figure 2). The C-6, C-8, and C-10 located in the ortho- and para-position of C-5 were different from compound $\mathbf{2 5}$ due to the influence of the hydroxyl group. Moreover, the absolute configuration of $\mathbf{2 6}$ was determined as $4 S$ from the CD spectrum of its aglycon [18], which had a negative Cotton effect. Thus, the structure of $\mathbf{2 6}$ was established as (4S)-4,5-dihydroxy- $\alpha$-tetralone-4$O$ - $\beta$-D-(6'-O-4"'-hydroxybenzoyl) glucopyranoside.

Compound 27 was isolated as a yellow powder, which had the molecular formula $\mathrm{C}_{23} \mathrm{H}_{24} \mathrm{O}_{11}$, established in HR-ESI-MS. Hydrolysis of $\mathbf{2 7}$ was similar to $\mathbf{2 5}$ and 26. Glucose was further confirmed by ${ }^{1} \mathrm{H}-,{ }^{13} \mathrm{C}-\mathrm{NMR}$, and the DEPT spectrum $\left(\delta_{\mathrm{H}} 4.81\left(\mathrm{~d}, J=7.5 \mathrm{~Hz}, \mathrm{H}-1^{\prime}\right) ; \delta_{\mathrm{C}} 104.4,75.2,78.0,72.0\right.$, $75.8,64.8)$. The correlation position between the aglycone and glucose was different from compounds 25 and 26, which was deduced to transfer to $\delta_{c} 148.3$ (C-5), implying the connection at the aryl ring of the tetralone by the HMBC spectrum. The relative configuration of the glucopyranose moiety was determined as $\beta$ by the coupling constant $(J=7.5 \mathrm{~Hz})$ of the anomeric proton. Furthermore, the ${ }^{1} \mathrm{H}-\mathrm{NMR}$ spectrum showed the AB-type aromatic proton signals at $\delta \mathrm{H} 7.40(\mathrm{~d}, J=9.1 \mathrm{~Hz}, \mathrm{H}-6)$ and 6.67 (d, $J=9.1 \mathrm{~Hz}, \mathrm{H}-7$ ) in this aryl ring. It was also observed that a new quaternary carbon signal appeared at $\delta_{\mathrm{C}} 159.3$ due to the $\mathrm{C}-8$ position in DEPT spectrum. It was also worth noting that the carbon signal at $\delta_{\mathrm{C}} 116.2$ (C-3", 5") not only had connections with H-3", 5" and H-2", 6", but also related with H-7 and H-4 (Figure 2) in HMBC. So we deduced that C-9 and C-3", 5" occurred in the same position. The absolute configuration of the chiral center at the C-4 position was deduced to be $S$ by CD spectrum analysis of its aglycon [18]. Thus, the structure of 27 was determined to be (4S)-4,5,8-thihydroxy- $\alpha$ tetralone 5-O- $\beta$-D-(6'-O-4"-hydroxybenzoyl) glucopyranoside. 
Table 1. ${ }^{1} \mathrm{H}-(400 \mathrm{MHz})$ and ${ }^{13} \mathrm{C}-(100 \mathrm{MHz}) \mathrm{NMR}$ data of 18, 25-27 in $\mathrm{CD}_{3} \mathrm{OD}$.

\begin{tabular}{|c|c|c|c|c|c|c|c|c|}
\hline \multirow{2}{*}{ No. } & \multicolumn{2}{|l|}{18} & \multicolumn{2}{|l|}{25} & \multicolumn{2}{|l|}{26} & \multicolumn{2}{|l|}{27} \\
\hline & $\delta_{H}(J$ in $\mathbf{H z})$ & $\delta \mathrm{C}$ & $\delta_{H}(J$ in $\mathbf{H z})$ & $\delta \mathbf{C}$ & $\delta_{H}(J$ in $\mathbf{H z})$ & $\delta \mathrm{C}$ & $\delta_{H}(J$ in $\mathbf{H z})$ & $\boldsymbol{\delta} \mathbf{C}$ \\
\hline 1 & - & 148.0 & - & 200.0 & - & 200.9 & - & 206.4 \\
\hline \multirow{2}{*}{2} & $7.72, \mathrm{~s}$ & 109.9 & $\begin{array}{l}\mathrm{H}_{\mathrm{ax}}: 2.87, \mathrm{ddd} \\
(4.5,8.9,17.5)\end{array}$ & 35.5 & $\begin{array}{c}\mathrm{H}_{\mathrm{ax}}: 3.03, \mathrm{ddd} \\
(5.0,13.4,17.0)\end{array}$ & 33.9 & $\begin{array}{l}\mathrm{H}_{\mathrm{ax}}: 3.01, \mathrm{ddd} \\
(5.9,12.9,17.6)\end{array}$ & 33.5 \\
\hline & & & $\begin{array}{l}\text { Heq: } 2.41, \text { ddd } \\
(4.5,6.5,17.5)\end{array}$ & & $\begin{array}{c}\mathrm{H}_{\mathrm{eq}}: 2.37, \mathrm{dt} \\
(3.6,17.0)\end{array}$ & & $\begin{array}{c}\mathrm{H}_{\mathrm{eq}}: 2.44, \mathrm{dt} \\
(3.6,17.6)\end{array}$ & \\
\hline \multirow{2}{*}{3} & - & 105.8 & $\begin{array}{c}\mathrm{H}_{\mathrm{ax}}: 2.34, \text { dddd } \\
(2.2,4.5,8.9,13.4)\end{array}$ & 31.5 & $\begin{array}{c}\mathrm{H}_{\mathrm{ax}}: 2.48, \text { dddd } \\
(1.3,3.2,4.7,12.6)\end{array}$ & 30.0 & $2.16, \mathrm{~m}$ & 30.3 \\
\hline & & & $\begin{array}{c}\text { Heq }_{\text {eq }} 2.28 \text {, dddd } \\
(3.8,4.5,6.5,13.4)\end{array}$ & & $\begin{array}{c}\mathrm{H}_{\mathrm{eq}}: 2.10, \mathrm{tt} \\
(4.2,12.6)\end{array}$ & & & \\
\hline 4 & - & 155.1 & 4.97, dd $(3.6,6.5)$ & 75.9 & $5.37, \mathrm{t}(2.9)$ & 69.9 & $5.32, \mathrm{t}(3.1)$ & 61.3 \\
\hline 5 & $\begin{array}{l}6.99, \mathrm{dd} \\
(1.0,7.8)\end{array}$ & 116.0 & $\begin{array}{c}7.65, \text { brd } \\
(7.6)\end{array}$ & 130.0 & - & 157.0 & - & 148.3 \\
\hline 6 & $7.40, \mathrm{t}(7.8)$ & 128.6 & $7.52, \mathrm{dt}(1.2,7.6)$ & 134.8 & $7.08, \mathrm{dd}(0.8,8.0)$ & 122.3 & $7.40, \mathrm{~d}(9.1)$ & 128.9 \\
\hline 7 & $\begin{array}{l}7.86, \mathrm{dd} \\
(1.0,7.8)\end{array}$ & 116.1 & $\begin{array}{c}7.43, \mathrm{dt} \\
(1.2,7.6)\end{array}$ & 129.4 & $\begin{array}{l}7.27, \mathrm{t} \\
(8.0)\end{array}$ & 130.6 & $\begin{array}{l}6.67, \mathrm{~d} \\
(9.1)\end{array}$ & 118.9 \\
\hline 8 & - & 158.0 & $7.93, \mathrm{dd}(1.2,7.6)$ & 127.9 & $7.46, \mathrm{dd}(0.8,8.0)$ & 118.9 & - & 159.3 \\
\hline 9 & 一 & 120.2 & - & 132.9 & - & 134.4 & - & 116.2 \\
\hline 10 & 一 & 131.1 & - & 143.9 & 一 & 129.6 & - & 135.5 \\
\hline $\mathbf{1}^{\prime}$ & $4.99, \mathrm{~d}(7.6)$ & 105.5 & $4.42, \mathrm{~d}(7.6)$ & 103.7 & $4.60, \mathrm{~d}(7.8)$ & 103.8 & $4.81, \mathrm{~d}(7.5)$ & 104.4 \\
\hline $2^{\prime}$ & $3.50, \mathrm{~m}$ & 78.9 & $3.34, \mathrm{~m}$ & 75.2 & $3.2, \mathrm{~m}$ & 75.3 & $\begin{array}{c}3.53, \mathrm{dd} \\
(8.8,16.5)\end{array}$ & 75.2 \\
\hline $3^{\prime}$ & $3.53, \mathrm{~m}$ & 75.0 & $3.36, \mathrm{dd}(2.5,7.0)$ & 78.1 & $3.38, \mathrm{~m}$ & 78.0 & $3.49, \mathrm{t}(8.6)$ & 78.0 \\
\hline $4^{\prime}$ & $3.43, \mathrm{~m}$ & 71.3 & $3.36, \mathrm{dd}(2.5,7.0)$ & 72.2 & $3.38, \mathrm{~m}$ & 72.1 & $\begin{array}{c}3.43, \mathrm{dd} \\
(10.6,16.2) \\
\end{array}$ & 72.0 \\
\hline $5^{\prime}$ & $3.48, \mathrm{~m}$ & 78.2 & $3.62, \mathrm{~m}$ & 75.5 & $3.65, \mathrm{~m}$ & 75.7 & $3.68, \mathrm{dt}(2.2,8.4)$ & 75.8 \\
\hline $6^{\prime} \mathbf{a}$ & $\begin{array}{c}3.96, \mathrm{dd} \\
(2.1,12.0)\end{array}$ & 62.5 & $\begin{array}{c}4.66, \mathrm{dd} \\
(2.2,11.8)\end{array}$ & 65.0 & $\begin{array}{c}4.64, \mathrm{dd} \\
(2.2,11.8)\end{array}$ & 65.0 & $\begin{array}{c}4.61, \mathrm{dd} \\
(2.2,11.8)\end{array}$ & 64.8 \\
\hline $6^{\prime} \mathrm{b}$ & $\begin{array}{c}3.77, \mathrm{dd} \\
(5.5,12.0)\end{array}$ & & $4.47, \mathrm{dd}(7.2,11.8)$ & & $4.43, \mathrm{dd}(6.8,11.8)$ & & $\begin{array}{c}4.40, \mathrm{dd} \\
(7.4,11.8) \\
\end{array}$ & \\
\hline $1 "$ & - & 171.8 & - & 122.2 & - & 121.9 & - & 122.1 \\
\hline $2 "$ & $\begin{array}{c}4.44, \mathrm{dq} \\
(3.6,17.7) \\
\end{array}$ & 62.8 & $\begin{array}{c}7.95, \mathrm{~d} \\
(8.8) \\
\end{array}$ & 132.9 & $\begin{array}{r}7.95, \mathrm{dt} \\
(2.6,8.8) \\
\end{array}$ & 133.0 & $\begin{array}{c}7.82, \mathrm{dt} \\
(2.7,8.8) \\
\end{array}$ & 132.9 \\
\hline $3^{\prime \prime}$ & $1.43, \mathrm{t}(7.2)$ & 14.5 & $6.84, \mathrm{~d}(8.8)$ & 116.3 & $6.83, \mathrm{dt}(2.6,8.8)$ & 116.2 & $6.81, \mathrm{dt}(2.7,8.8)$ & 116.2 \\
\hline $4^{\prime \prime}$ & - & - & - & 163.7 & - & 163.6 & - & 163.7 \\
\hline $5 "$ & - & - & $6.84, \mathrm{~d}(8.8)$ & 116.3 & $6.83, \mathrm{dt}(2.6,8.8)$ & 116.2 & $6.81, \mathrm{dt}(2.7,8.8)$ & 116.2 \\
\hline $6^{\prime \prime}$ & - & - & $7.95, \mathrm{~d}(8.8)$ & 132.9 & $7.95, \mathrm{dt}(2.6,8.8)$ & 133.0 & $7.82, \mathrm{dt}(2.7,8.8)$ & 132.9 \\
\hline 7" & - & - & - & 167.9 & - & 168.1 & - & 167.8 \\
\hline
\end{tabular}

\subsection{Cytotoxic Activity}

It was reported that green husks of Juglans mandshurica Maxim had an obvious effect on liver cancer. HepG-2 is a kind of human liver cancer cells which are often applied to evaluate cytotoxic activity in vitro [20,21].Therefore, we tested the cytotoxicity of compounds 1-27 against HepG-2 by the MTT method and compared with references for some compounds [22-24]. 
The results were shown that most naphthoquinones in an aglycone form exhibited better cytotoxicity in vitro than naphthalenyl glucosides with $\mathrm{IC}_{50}$ values in the range of $7.33-88.23 \mu \mathrm{M}$. None of them had better $\mathrm{IC}_{50}$ values than cisplatin itself, but some naphthoquinone aglycones including juglone (1) and 3,5-dihydroxy-1,4-naphthoquinone (6) had obvious inhibition effects similar with cisplatin. The IC50 value of juglone was $8.14 \pm 1.95$, and that of 3,5-dihydroxy-1,4-naphthoquinone was $7.33 \pm 0.52$ at $24 \mathrm{~h}$ of MTT assay, respectively (Table 2). Furthermore, these naphthoquinone aglycones with the structural features of 2,3-unsaturated moieties showed better and stronger cytotoxicity effects compared to other tetralones with a partial saturated aryl ring.

Table 2. Cytotoxicities of compound 1-27 from J. mandshurica Maxim on HepG-2 cells lines.

\begin{tabular}{|c|c|c|c|c|c|c|c|}
\hline Compd. & $\begin{array}{c}\text { Structural } \\
\text { Features }\end{array}$ & $\mathrm{IC}_{50}(\mu \mathrm{M})^{\mathrm{a}}$ & SD $^{b}$ & Compd. & $\begin{array}{c}\text { Structural } \\
\text { Features }\end{array}$ & $\mathrm{IC}_{50}(\mu \mathrm{M})^{\mathrm{a}}$ & SD $^{b}$ \\
\hline 1 & & 8.14 & 1.95 & 15 & & NA & 3.21 \\
\hline 2 & & 68.72 & 1.50 & 16 & & NA & - \\
\hline 3 & & 16.11 & 3.54 & 17 & & 83.32 & 4.54 \\
\hline 4 & & 18.83 & 2.98 & 18 & & NA & - \\
\hline 5 & & 15.37 & 1.63 & 19 & & 78.61 & 2.38 \\
\hline 6 & & 7.33 & 0.52 & 20 & & NA & - \\
\hline 7 & & 43.54 & 0.15 & 21 & & NA & - \\
\hline 8 & & 22.38 & 0.66 & 22 & & NA & - \\
\hline 9 & & 30.42 & 2.48 & 23 & & NA & - \\
\hline 10 & & 32.51 & 0.46 & 24 & & NA & - \\
\hline 11 & & 34.80 & 0.33 & 25 & $\begin{array}{r}\mathrm{OR} \\
\mathrm{R}=\mathrm{H}(\mathrm{Glc})\end{array}$ & NA & - \\
\hline 12 & & 56.87 & 4.27 & 26 & & NA & - \\
\hline 13 & & 67.95 & 3.22 & 27 & & NA & - \\
\hline 14 & $\mathrm{R}=\mathrm{H}\left(\mathrm{CH}_{3}\right) \quad$ & 88.23 & 1.90 & $\mathrm{PC}^{\mathrm{c}}$ & metal complex & 4.51 & 0.38 \\
\hline
\end{tabular}

${ }^{a} \mathrm{IC}_{50}$, concentration required for inhibiting growth of $\mathrm{HepG}-2$ by $50 \%$ (in $\mu \mathrm{M}$ ). These results are average results of three experiments; ${ }^{\mathrm{b}} \mathrm{SD}$, standard deviation; ${ }^{\mathrm{c}} \mathrm{PC}$, positive control (cisplatin); $\mathrm{NA}=$ not active.

Above results were merely obtained from the distinction of the mother nucleus structure. The different nature of the substituent in the naphthoquinone also seemed to influence the cytotoxicity activity. One or two phenolic hydroxyl groups without other substituents, which were introduced to a set of analogues (compounds $\mathbf{1}, \mathbf{3}, \mathbf{4}, \mathbf{5}$ and $\mathbf{6}$ ), were responsible for the lower $\mathrm{IC}_{50}$ value and better inhibition effect. However, it was worth noting that the position and number of the hydroxyl group had a limited or negligible effect on HepG-2 inhibitory activities. For example, the $\mathrm{IC}_{50}$ value of compound $\mathbf{1}$ with one hydroxyl group was similar with compound $\mathbf{6}$ with two hydroxyl groups; the $\mathrm{IC}_{50}$ value of compound $\mathbf{3}$ which was substituted at the 5,8-position was similar to compound $\mathbf{5}$ which was substituted at the 2, 5-position. In addition, the introduction of the methoxy or ethyoxyl group to some naphthoquinones with 2, 3-unsaturated moieties resulted in a slight decrease in the inhibition effect, including compounds 7, 8, 9 and 10. Among of them, compound 2 had the worst effect on the inhibition of HepG-2 cells.

A majority of naphthoquinone glycosides exhibited no activity against HepG-2 cells. These results were in accordance with previous reports [24] that the most active compounds were those without the linkage of saccharide. Some glycosides like compound $\mathbf{1 7}$ and 19, of which aglycone was the integrated 
conjugation structure assigned to the naphthols, possessed slight cytotoxicity in vitro with IC50 values of $83.3 \pm 4.54$ and $78.61 \pm 2.38$, respectively. However, some naphthols substituted with more than one saccharide or other groups, except for phenolic hydroxyl groups, had no cytotoxic activity against HepG-2 cells. The results indicated that there were differences in cytotoxic activity between these naphthoquinone glycosides according to the way of substitution and the type of aglycone.

\section{Experimental Section}

\subsection{General Information}

High resolution-electron spray ionization (HR-ESI) mass spectra were obtained on a micromass LCT spectrometer. ${ }^{1} \mathrm{H}-,{ }^{13} \mathrm{C}-\mathrm{NMR}$, DEPT, HSQC, HMBC were obtained on Bruker DPX 400 NMR instrument (Bruker, Rheinstetten, Germany). Chemical shifts $(\delta)$ are expressed in parts per million (ppm) using tetramethyl-silane (TMS) as an internal standard. Spin multiplicities are given as $\mathrm{s}$ (singlet), d (doublet), $\mathrm{t}$ (triplet), dd (double doublet), and $\mathrm{m}$ (multiplet). The UV spectra were recorded on a Thermo Scientific Evolution 300 UV-visible spectrophotometer (Thermo Fisher Scientific, Waltham, MA, USA). Optical rotations were recorded using an Anton Paar-MCP 600 polarimeter $\mathrm{r}$ (Anton Paar, Graz, Austria). GC was run on Agilent 7890A Gas Chromatograph System (Agilent Technologies, Santa Clara, CA, USA). CD spectra were obtained on a Bio-Logic MOS-450 CD spectrometer. The IR spectra were obtained on a Shimadzu FTIR-8400S spectrometer (Shimadzu, Kyoto, Japan). Melting points are uncorrected and were obtained on a Hoover capillary melting point. HPLC chromatograms were obtained with an Agilent Technologies 1260 infinity HPLC system (Agilent Technologies, Germany) and semi-preparative HPLC (Waters, 515-2414, Milford, MA, USA) was performed using a Hypersil-ODS II column (300 mm $\times 20 \mathrm{~mm}$ i.d., $10 \mu \mathrm{m}$, Ylite, Dalian, China). De-ionized water was prepared with a Milli-Q system (Milford, MA, USA). HepG-2 cell line obtained from Institute of Biochemistry and Cell Biology (Shanghai, China) were grown in Dulbecco's Modified Eagle's Medium (DMEM) (Hyclone, NRH0020), supplemented with 5\% fetal bovine serum and 1\% antibiotic mixture comprising penicillin-streptomycin, in a humidified atmosphere at $37{ }^{\circ} \mathrm{C}$ with $5 \% \mathrm{CO}_{2}$. A multiscan microplate reader (Thermo Labsystems, Helsinki, Finland) was used for the MTT assays. The solvents used for open column isolation, such as ethyl acetate, methanol, acetonitrile, and chloroform were purchased from Merck (Darmstadt, Germany). MTT and Dulbecco's Modified Dagle's Medium (DMEM) were purchased from Sigma Chemical Co. (St. Louis, MO, USA).

\subsection{Plant Material}

The green husks of $J$. mandshurica were collected in late July from the Changbai Mountains (Jilin, China), and identified by the professor Zhen-Yue Wang. The dried samples were grounded into fine powder (60 mesh), and dried thoroughly in an oven at $40{ }^{\circ} \mathrm{C}$ for 3 days.

\subsection{Extraction and Isolation}

The air-dried parts of materials $(10.0 \mathrm{~kg})$ were powdered and soaked in $80 \mathrm{~L}_{\text {of }} \mathrm{CHCl}_{3}$ for 7 days. The extraction was repeated three times and then concentrated under reduced pressure to afford the $\mathrm{CHCl}_{3}$ extract (350 g). $\mathrm{CHCl}_{3}$ extract was subjected to silica gel (200-300 mesh) column chromatography 
(CC), eluted with PE:EtOAc $(40: 1 \rightarrow 1: 1, v / v)$, to create twelve fractions (Fr1-Fr12). Fraction 3 (15.50 g) was subjected to silica gel (200-300 mesh) CC, eluted with PE:EtOAc $(40: 1 \rightarrow 1: 1, v / v)$, to give fractions 3a-3c. Compounds 1 (245.4 mg), 3 (12.1 mg), 4 (33.8 mg), and 8 (11.8 mg), were isolated from fraction 3a by repeated column chromatography over silica gel, eluted with PE:EtOAc $(40: 1 \rightarrow 10: 1, v / v)$. Fraction 6 (12.80 g) was subjected to silica gel (200-300 mesh) CC, eluted with PE:EtOAc $(20: 1 \rightarrow 5: 1, v / v)$ to obtain compounds $5(15.5 \mathrm{mg}), 7(22.0 \mathrm{mg}), \mathbf{9}(25.3 \mathrm{mg}), \mathbf{1 0}(15.2 \mathrm{mg})$, 12 (75.0 mg), and 13 (23.4 mg). Fraction 8 (8.92 g) was subjected to silica gel (200-300 mesh) CC, eluted with PE:EtOAc $(5: 1 \rightarrow 1: 1, v / v)$ to obtain $2(5.8 \mathrm{mg}), \mathbf{6}(7.7 \mathrm{mg}), \mathbf{1 1}(6.8 \mathrm{mg})$, and $\mathbf{1 4}(12.8 \mathrm{mg})$.

The residue of materials were reflux extracted three times with $60 \mathrm{~L} \mathrm{EtOH}(95 \% v / v)$, then concentrated under reduced pressure to afford the EtOH extract $(750 \mathrm{~g})$. The EtOH extract was subjected to Macroporous Resin AB-8 CC, sequentially eluted with $\mathrm{H}_{2} \mathrm{O}, 30 \% \mathrm{EtOH}$, and 95\% EtOH. Compounds 15-27 were isolated from $30 \% \mathrm{EtOH}$ fraction. Next, the isolation procedure of these compounds was explained. The $30 \% \mathrm{EtOH}$ elution fraction was evaporated and concentrated to yield a crude residue (98 g). The residue was further purified by octadecyl silane (ODS) $\mathrm{CC}$ with $\mathrm{MeOH} / \mathrm{H}_{2} \mathrm{O}(2: 8 \rightarrow 1: 0)$ to give eleven fractions (Fr1-Fr11). Fraction 2 (6.50 g) was fractionated by ODS CC with $\mathrm{MeOH} / \mathrm{H}_{2} \mathrm{O}$ $(2: 8 \rightarrow 1: 0)$ to afford a number of subfractions: $2 \mathrm{a}, 2 \mathrm{~b}, 2 \mathrm{c}$. Subfraction $2 \mathrm{c}(1.0 \mathrm{~g})$ was subjected to semi-preparative HPLC chromatography $\left(\mathrm{MeOH} / \mathrm{H}_{2} \mathrm{O} 35: 65, v / v\right.$, flow rate $3 \mathrm{~mL} / \mathrm{min}$ ) to yield compounds $15\left(5.3 \mathrm{mg}, \mathrm{t}_{\mathrm{R}}=21 \mathrm{~min}\right), \mathbf{1 6}\left(6.1 \mathrm{mg}, \mathrm{t}_{\mathrm{R}}=23 \mathrm{~min}\right)$, and then subjected to semi-preparative HPLC chromatography $\left(\mathrm{MeOH} / \mathrm{H}_{2} \mathrm{O} 45: 55, v / v\right.$, flow rate $\left.3 \mathrm{~mL} / \mathrm{min}\right)$ to yield compound $19\left(3.2 \mathrm{mg}, \mathrm{t}_{\mathrm{R}}=\right.$ $22 \mathrm{~min})$. Fraction $5(9.40 \mathrm{~g})$ was fractionated twice by ODS CC with $\mathrm{MeOH} / \mathrm{H}_{2} \mathrm{O}(2: 8 \rightarrow 1: 0)$ to afford a number of subfractions: $5 \mathrm{a}, 5 \mathrm{~b}, 5 \mathrm{c}, 5 \mathrm{~d}$ and $5 \mathrm{e}$. Subfraction $5 \mathrm{~b}(0.84 \mathrm{~g})$ was purified by semi-preparative HPLC chromatography $\left(\mathrm{MeOH} / \mathrm{H}_{2} \mathrm{O} 45: 55, v / v\right.$, flow rate $\left.3 \mathrm{~mL} / \mathrm{min}\right)$ to yield compound $24(4.7 \mathrm{mg}$, $\left.t_{R}=32 \mathrm{~min}\right)$ and purified by semi-preparative HPLC chromatography $\left(\mathrm{MeOH} / \mathrm{H}_{2} \mathrm{O} 55: 45, v / v\right.$, flow rate $3 \mathrm{~mL} / \mathrm{min})$ to obtain compound $17\left(4.3 \mathrm{mg}, \mathrm{t}_{\mathrm{R}}=25 \mathrm{~min}\right)$. Similarly, Subfraction $5 \mathrm{c}$ was purified by semi-preparative HPLC chromatography $\left(\mathrm{MeOH} / \mathrm{H}_{2} \mathrm{O} 70: 30, v / v\right.$, flow rate $3 \mathrm{~mL} / \mathrm{min}$, $\left.\mathrm{t}_{\mathrm{R}}=25 \mathrm{~min}\right)$ to yield compounds $18\left(4.5 \mathrm{mg}, \mathrm{t}_{\mathrm{R}}=13 \mathrm{~min}\right), \mathbf{2 6}\left(2.8 \mathrm{mg}, \mathrm{t}_{\mathrm{R}}=38 \mathrm{~min}\right), \mathbf{2 5}\left(3.1 \mathrm{mg}, \mathrm{t}_{\mathrm{R}}=40 \mathrm{~min}\right)$, and 27 $\left(5.9 \mathrm{mg}, \mathrm{t}_{\mathrm{R}}=42 \mathrm{~min}\right)$. Fraction $8(5.70 \mathrm{~g})$ was subjected to silica gel (200-300 mesh) CC, eluted with $\mathrm{CH}_{2} \mathrm{Cl}_{2}: \mathrm{MeOH}(5: 1 \rightarrow 0: 1, v / v)$ to afford compounds $\mathbf{2 0}$ (7.5 mg), 21 (5.3 mg), 22 (4.6 mg), 23 (4.4 mg).

\subsection{Spectral Data}

Juglone (1). Orange needle crystal, ${ }^{1} \mathrm{H}-\mathrm{NMR}\left(\mathrm{CDCl}_{3}, 400 \mathrm{MHz}\right) \delta(\mathrm{ppm}): 6.99(2 \mathrm{H}, \mathrm{d}, J=12.2 \mathrm{~Hz}, \mathrm{H}-2,3)$, $7.27(1 \mathrm{H}, \mathrm{dd}, J=1.9,7.7 \mathrm{~Hz}, \mathrm{H}-6), 7.65(1 \mathrm{H}, \mathrm{t}, J=7.6 \mathrm{~Hz}, \mathrm{H}-7), 7.63(1 \mathrm{H}, \mathrm{dd}, J=7.6,7.7 \mathrm{~Hz}, \mathrm{H}-8)$, $11.90(1 \mathrm{H}, \mathrm{s}, 5-\mathrm{OH}) .{ }^{13} \mathrm{C}-\mathrm{NMR}\left(\mathrm{CDCl}_{3}, 100 \mathrm{MHz}\right) \delta(\mathrm{ppm}): 190.3(\mathrm{C}-1), 138.7(\mathrm{C}-2), 139.6(\mathrm{C}-3)$, 184.3 (C-4), 161.5 (C-5), 124.5 (C-6), 136.6 (C-7), 119.2 (C-8), 115.1 (C-9), 131.8 (C-10).

5-Methoxy-1,4-naphthoquinone (2). Light yellow powder, ${ }^{1} \mathrm{H}-\mathrm{NMR}\left(\mathrm{CDCl}_{3}, 400 \mathrm{MHz}\right) \delta$ : $7.58(1 \mathrm{H}, \mathrm{d}$, $J=7.6 \mathrm{~Hz}, \mathrm{H}-2), 7.48(1 \mathrm{H}, \mathrm{d}, J=7.6 \mathrm{~Hz}, \mathrm{H}-3), 6.73(1 \mathrm{H}$, br.d, $J=7.7 \mathrm{~Hz}, \mathrm{H}-6), 7.36(1 \mathrm{H}, \mathrm{t}$, $J=7.7 \mathrm{~Hz}, \mathrm{H}-7), 7.42(1 \mathrm{H}$, br.d, $J=7.7 \mathrm{~Hz}, \mathrm{H}-8), 3.83\left(3 \mathrm{H}, \mathrm{s}, 5-\mathrm{OCH}_{3}\right), 11.82(1 \mathrm{H}, \mathrm{s}, 5-\mathrm{OH})$. ${ }^{13} \mathrm{C}-\mathrm{NMR}\left(\mathrm{CDCl}_{3}, 100 \mathrm{MHz}\right) \delta(\mathrm{ppm}): 190.4$ (C-1), 138.3 (C-2), 139.3 (C-3), 186.3 (C-4), 161.2 (C-5), 119.2 (C-6), 124.3 (C-7), 136.1 (C-8), 131.4 (C-9), 114.0 (C-10), 55.4 (5-OCH3). 
5,8-Dihydroxy-1,4-naphthoquinone (3). Light yellow powder, ${ }^{1} \mathrm{H}-\mathrm{NMR}\left(\mathrm{CDCl}_{3}, 400 \mathrm{MHz}\right) \delta(\mathrm{ppm})$ : 7.13 (4H, s, H-2, 3, 6, 7). ${ }^{13} \mathrm{C}-\mathrm{NMR}\left(\mathrm{CDCl}_{3}, 100 \mathrm{MHz}\right) \delta(\mathrm{ppm}): 173.1$ (C-1, 4, 5, 8), 134.4 (C-2, 3, 6, 7), 112. $0(\mathrm{C}-9,10)$.

2-Hydroxy-1, 4-naphthoquinone (4). Light yellow powder, ${ }^{1} \mathrm{H}-\mathrm{NMR}\left(\mathrm{CDCl}_{3}, 400 \mathrm{MHz}\right) \delta(\mathrm{ppm}): 7.38$ $(1 \mathrm{H}, \mathrm{s}, \mathrm{H}-3), 8.13(2 \mathrm{H}, \mathrm{d}, J=7.3 \mathrm{~Hz}, \mathrm{H}-5,8), 7.82(1 \mathrm{H}, \mathrm{m}, \mathrm{H}-6), 7.74(1 \mathrm{H}, \mathrm{m}, \mathrm{H}-7) .{ }^{13} \mathrm{C}-\mathrm{NMR}\left(\mathrm{CDCl}_{3}\right.$, $100 \mathrm{MHz}) \delta(\mathrm{ppm}): 182.2$ (C-1), 156.5 (C-2), 110.7 (C-3), 185.0 (C-4), 135.3 (C-5), 126.8 (C-6), 126.7 (C-7), 133.4 (C-8), 130.0 (C-9), 129.5 (C-10).

2,5-Dihydroxy-1, 4-naphthoquinone (5). Light yellow powder, ${ }^{1} \mathrm{H}-\mathrm{NMR}\left(\mathrm{CDCl}_{3}, 400 \mathrm{MHz}\right) \delta$ (ppm): 6.12 $(1 \mathrm{H}, \mathrm{s}, \mathrm{H}-3), 7.23(1 \mathrm{H}, \mathrm{d}, J=8.2 \mathrm{~Hz}, \mathrm{H}-6), 7.57(1 \mathrm{H}, \mathrm{m}, \mathrm{H}-7), 7.40(1 \mathrm{H}, \mathrm{d}, J=7.6 \mathrm{~Hz}, \mathrm{H}-8), 12.10(1 \mathrm{H}$, s, 5-OH). ${ }^{13} \mathrm{C}-\mathrm{NMR}\left(\mathrm{CDCl}_{3}, 100 \mathrm{MHz}\right) \delta$ (ppm): 180.3 (C-1), 160.2 (C-2), 110.4 (C-3), 191.7 (C-4), 159.3 (C-5), 124.2 (C-6), 135.3 (C-7), 118.2 (C-8), 130.3 (C-9), 113.7 (C-10).

3,5-Dihydroxy-1, 4-naphthoquinone (6). Light yellow powder, ${ }^{1} \mathrm{H}-\mathrm{NMR}\left(\mathrm{CDCl}_{3}, 400 \mathrm{MHz}\right) \delta(\mathrm{ppm})$ : $6.14(1 \mathrm{H}, \mathrm{s}, \mathrm{H}-2), 7.26(1 \mathrm{H}, \mathrm{d}, J=7.8 \mathrm{~Hz}, \mathrm{H}-6), 7.66(1 \mathrm{H}, \mathrm{t}, J=7.8 \mathrm{~Hz}, \mathrm{H}-7), 7.43(1 \mathrm{H}, \mathrm{d}, J=7.8 \mathrm{~Hz}$, $\mathrm{H}-8), 12.02(1 \mathrm{H}, \mathrm{s}, 5-\mathrm{OH}) .{ }^{13} \mathrm{C}-\mathrm{NMR}\left(\mathrm{CDCl}_{3}, 100 \mathrm{MHz}\right) \delta(\mathrm{ppm}): 183.0(\mathrm{C}-1), 160.0(\mathrm{C}-2), 111.4$ (C-3), 185.3 (C-4), 160.3 (C-5), 122.2 (C-6), 136.0 (C-7), 117.0 (C-8), 132.5 (C-9), 114.2 (C-10).

3-Methoxy juglone (7). Orange powder, ${ }^{1} \mathrm{H}-\mathrm{NMR}\left(\mathrm{CDCl}_{3}, 400 \mathrm{MHz}\right) \delta(\mathrm{ppm}): 6.12(1 \mathrm{H}, \mathrm{s}, \mathrm{H}-2), 7.27$ $(1 \mathrm{H}, \mathrm{dd}, J=7.5,1.2 \mathrm{~Hz}, \mathrm{H}-6), 7.62(1 \mathrm{H}, \mathrm{t}, J=7.5 \mathrm{~Hz}, \mathrm{H}-7), 7.67(1 \mathrm{H}, \mathrm{d}, J=7.5,1.2 \mathrm{~Hz}, \mathrm{H}-8), 3.90$ $\left(3 \mathrm{H}, \mathrm{s}, \mathrm{OCH}_{3}\right), 11.75(1 \mathrm{H}, \mathrm{s}, \mathrm{OH}-5) .{ }^{13} \mathrm{C}-\mathrm{NMR}\left(\mathrm{CDCl}_{3}, 100 \mathrm{MHz}\right) \delta(\mathrm{ppm}): 184.9(\mathrm{C}-1), 110.5(\mathrm{C}-2)$, 160.6 (C-3), 183.9 (C-4), 162.0 (C-5), 123.9 (C-6), 138.2 (C-7), 118.9 (C-8), 132.1 (C-9), 114.3 (C-10), $56.6\left(3-\mathrm{OCH}_{3}\right)$.

2-Methoxy juglone (8). Orange-red needle crystal, ${ }^{1} \mathrm{H}-\mathrm{NMR}\left(\mathrm{CDCl}_{3}, 400 \mathrm{MHz}\right) \delta(\mathrm{ppm}): 6.11(1 \mathrm{H}, \mathrm{s}$, H-3), 7.28 (1H, dd, $J=8,1.2 \mathrm{~Hz}, \mathrm{H}-6), 7.58(1 \mathrm{H}, \mathrm{t}, J=8 \mathrm{~Hz}, \mathrm{H}-7), 7.67$ (1H, dd, $J=8,1.2 \mathrm{~Hz}, \mathrm{H}-8)$, $3.93(3 \mathrm{H}, \mathrm{s}, 2-\mathrm{OCH} 3), 12.22(1 \mathrm{H}, \mathrm{s}, 5-\mathrm{OH}) .{ }^{13} \mathrm{C}-\mathrm{NMR}\left(\mathrm{CDCl}_{3}, 100 \mathrm{MHz}\right) \delta(\mathrm{ppm}): 179.3(\mathrm{C}-1), 161.1$ (C-2), 109.5 (C-3), 190.8 (C-4), 161.1 (C-5), 125.2 (C-6), 135.4 (C-7), 119.5 (C-8), 131.1 (C-9), 114.2 $(\mathrm{C}-10), 56.6\left(2-\mathrm{OCH}_{3}\right)$.

3-Ethoxy juglone (9). Orange powder, ${ }^{1} \mathrm{H}-\mathrm{NMR}\left(\mathrm{CDCl}_{3}, 400 \mathrm{MHz}\right) \delta(\mathrm{ppm}): 6.13(\mathrm{H}, \mathrm{s}, \mathrm{H}-2), 7.24(1 \mathrm{H}$, $\mathrm{dd}, J=7.5,1.2 \mathrm{~Hz}, \mathrm{H}-6), 7.62(1 \mathrm{H}, \mathrm{t}, J=7.5 \mathrm{~Hz}, \mathrm{H}-7), 7.62(1 \mathrm{H}, \mathrm{dd}, J=7.5,1.2 \mathrm{~Hz}, \mathrm{H}-8), 4.11(3 \mathrm{H}, \mathrm{q}$, $J=6.9 \mathrm{~Hz}, \mathrm{H}-1 \mathrm{a}), 1.60(2 \mathrm{H}, \mathrm{t}, J=6.9 \mathrm{~Hz}, \mathrm{H}-2 \mathrm{a}), 11.78(1 \mathrm{H}, \mathrm{s}, \mathrm{OH}-5) .{ }^{13} \mathrm{C}-\mathrm{NMR}\left(\mathrm{CDCl}_{3}, 100 \mathrm{MHz}\right) \delta$ (ppm): 185.1 (C-1), 110.8 (C-2), 159.3 (C-3), 184.1 (C-4), 161.9 (C-5), 123.8 (C-6), 118.8 (C-7), 137.1 (C-8), 132.0 (C-9), 114.3 (C-10), 65.6 (C-1a), 13.9 (C-2a).

2-Ethoxy juglone (10). Light yellow flaky crystal, ${ }^{1} \mathrm{H}-\mathrm{NMR}\left(\mathrm{CDCl}_{3}, 400 \mathrm{MHz}\right) \delta(\mathrm{ppm}): 6.08(1 \mathrm{H}, \mathrm{s}$, H-3), 7.67 (1H, dd, $J=7.5,1.2 \mathrm{~Hz}, \mathrm{H}-6), 7.59(1 \mathrm{H}, \mathrm{t}, J=7.5 \mathrm{~Hz}, \mathrm{H}-7), 7.26(1 \mathrm{H}, \mathrm{dd}, J=7.5,1.2 \mathrm{~Hz}$, $\mathrm{H}-8), 4.12\left(2 \mathrm{H}, \mathrm{q}, J=7.2 \mathrm{~Hz},-\mathrm{OCH}_{2}\right), 1.53\left(3 \mathrm{H}, \mathrm{t}, J=7.2 \mathrm{~Hz},-\mathrm{CH}_{3}\right),{ }^{13} \mathrm{C}-\mathrm{NMR}\left(\mathrm{CDCl}_{3}, 100 \mathrm{MHz}\right)$ $\delta$ (ppm): 190.0 (C-1), 160.1 (C-2), 109.3 (C-3), 179.2 (C-4), 161.0 (C-5), 114.6 (C-6), 135.3 (C-7), 125.0 (C-8), 131.1 (C-9), 119.0 (C-10), 65.5 (C-1'), 13.8 (C-2'). 
Engelharquinone (11). Yellow needle crystal, ${ }^{1} \mathrm{H}-\mathrm{NMR}\left(\mathrm{CDCl}_{3}, 400 \mathrm{MHz}\right) \delta(\mathrm{ppm}): 6.92(1 \mathrm{H}, \mathrm{d}$, $J=8.4 \mathrm{~Hz}, \mathrm{H}-2), 7.48(1 \mathrm{H}, \mathrm{dd}, J=7.4,8.4 \mathrm{~Hz}, \mathrm{H}-3), 7.14(1 \mathrm{H}, \mathrm{d}, J=7.4 \mathrm{~Hz}, \mathrm{H}-4), 7.25(1 \mathrm{H}, \mathrm{dd}$, $J=7.6,1.9 \mathrm{~Hz}, \mathrm{H}-8), 7.59$ (1H, dd, $J=7.6,7.4 \mathrm{~Hz}, \mathrm{H}-9), 7.65$ (1H, dd, $J=7.6,1.9 \mathrm{~Hz}, \mathrm{H}-10), 4.23$ $(1 \mathrm{H}, \mathrm{d}, J=3.1 \mathrm{~Hz}, \mathrm{H}-12), 3.08(1 \mathrm{H}, \mathrm{dd}, J=3.8,10.6 \mathrm{~Hz}, \mathrm{H}-14 \mathrm{a}), 3.04(1 \mathrm{H}, \mathrm{brd}, J=3.8,10.6 \mathrm{~Hz}$, $\mathrm{H}-14 \mathrm{~b}), 11.50(1 \mathrm{H}, \mathrm{s}, 1-\mathrm{OH}), 4.80(1 \mathrm{H}, \mathrm{s}, 5-\mathrm{OH}), 11.52(1 \mathrm{H}, \mathrm{s}, 7-\mathrm{OH}) .{ }^{13} \mathrm{C}-\mathrm{NMR}\left(\mathrm{CDCl}_{3}, 100 \mathrm{MHz}\right) \delta$ (ppm): 198.1 (C-13), 188.8 (C-6), 180.5 (C-11), 163.5 (C-1), 162.1 (C-7), 154.4 (C-5a), 148.7 (C-11a), 146.3 (C-4a), 137.3 (C-9), 136.8 (C-3), 132.6 (C-11a), 125.2 (C-8), 120.4 (C-10), 119.4 (C-2), 115.3 (C-6a), 110.5 (C-13a), 82.0 (C-5), 54.1 (C-14), 52.6 (C-12).

(S)-Regiolone (12). White powder, ${ }^{1} \mathrm{H}-\mathrm{NMR}$ (DMSO- $\left.d 6,400 \mathrm{MHz}\right) \delta(\mathrm{ppm}): 2.74(2 \mathrm{H}, \mathrm{m}, \mathrm{H}-2), 2.20$ $(1 \mathrm{H}, \mathrm{m}, \mathrm{H}-3 \mathrm{a}), 2.00(1 \mathrm{H}, \mathrm{m}, \mathrm{H}-3 \mathrm{~b}), 4.76(1 \mathrm{H}, \mathrm{m}, \mathrm{H}-4), 7.06(1 \mathrm{H}, \mathrm{d}, J=8.0 \mathrm{~Hz}, \mathrm{H}-5), 7.53(1 \mathrm{H}, \mathrm{t}$, $J=8.0,8.2 \mathrm{~Hz}, \mathrm{H}-6), 6.83(1 \mathrm{H}, \mathrm{d}, J=8.2 \mathrm{~Hz}, \mathrm{H}-7), 5.60(\mathrm{H}, \mathrm{s}, \mathrm{OH}-4), 12.42(1 \mathrm{H}, \mathrm{s}, \mathrm{OH}-8)$. ${ }^{13} \mathrm{C}-\mathrm{NMR}$ (DMSO-d6, $\left.100 \mathrm{MHz}\right) \delta$ (ppm): 205.5 (C-1), 35.5 (C-2), 31.8 (C-3), 66.6 (C-4), 117.8 (C-5), 137.0 (C-6), 116.1 (C-7), 162.0 (C-8), 149.4 (C-9), 115.3 (C-10).

(4S)-4-Hydroxy- $\alpha$-tetralone (13). Claybank oil substance, ${ }^{1} \mathrm{H}-\mathrm{NMR}\left(\mathrm{CDCl}_{3}, 400 \mathrm{MHz}\right) \delta(\mathrm{ppm}): 2.53$ (1H, ddd, $J=17.8,9.6,4.8 \mathrm{~Hz}, \mathrm{H}-2 \mathrm{a}), 2.86$ (1H, ddd, $J=17.8,7.5,4.6 \mathrm{~Hz}, \mathrm{H}-2), 2.15$ (1H, m, H-3a), 2.37 (1H, m, H-3b), 4.95 (1H, dd, $J=8.1,3.9$ Hz, H-4), 7.52 (1H, m, H-5, 6), 7.38 (1H, m, H-7), 7.98 $(1 \mathrm{H}$, brd, $J=7.8 \mathrm{~Hz}, \mathrm{H}-8) .{ }^{13} \mathrm{C}-\mathrm{NMR}\left(\mathrm{CDCl}_{3}, 100 \mathrm{MHz}\right) \delta(\mathrm{ppm}): 197.8$ (C-1), $35.2(\mathrm{C}-2), 32.3(\mathrm{C}-3)$, 67.7 (C-4), 126.9 (C-5), 134.2 (C-6), 127.3 (C-7), 128.5 (C-8), 130.8 (C-9), 145.5 (C-10).

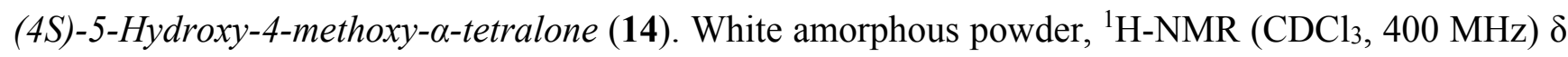
(ppm): 2.63 (1H, m, H-2), 2.87 (1H, m, H-2), 2.11 (1H, m, 3a), 2.24 (1H, m, H-3b), 4.98 (1H, m, H-4), $7.07(1 \mathrm{H}, \mathrm{dd}, J=8.0,1.0 \mathrm{~Hz}, \mathrm{H}-6), 7.58(1 \mathrm{H}, \mathrm{dd}, J=8.0,1.0 \mathrm{~Hz}, \mathrm{H}-7), 7.33(1 \mathrm{H}, \mathrm{t}, J=8.0 \mathrm{~Hz}, \mathrm{H}-8)$, $8.55(1 \mathrm{H}, \mathrm{s}, 5-\mathrm{OH}), 3.57\left(3 \mathrm{H}, \mathrm{s}, 4-\mathrm{OCH}_{3}\right) .{ }^{13} \mathrm{C}-\mathrm{NMR}\left(\mathrm{CDCl}_{3}, 100 \mathrm{MHz}\right) \delta(\mathrm{ppm}): 196.2(\mathrm{C}-1), 35.6$ (C-2), 27.3 (C-3), 80.2 (C-4), 156.3 (C-5), 122.32 (C-6), 129.6 (C-7), 119.3 (C-8), 132.5 (C-9), 126.7 (C-10), $55.3(\mathrm{C}-11)$.

1,4,5-Trihydroxynaphthalene-1,4-di-O- $\beta$-D-glucopyranoside (15). Yellow amorphous powder, ${ }^{1} \mathrm{H}-\mathrm{NMR}$ $\left(\mathrm{CD}_{3} \mathrm{OD}, 400 \mathrm{MHz}\right) \delta(\mathrm{ppm}): 7.16(1 \mathrm{H}, \mathrm{d}, J=8.8 \mathrm{~Hz}, \mathrm{H}-2), 7.30(1 \mathrm{H}, \mathrm{d}, J=8.8 \mathrm{~Hz}, \mathrm{H}-3), 6.85(1 \mathrm{H}, \mathrm{dd}$, $J=7.6,1.2 \mathrm{~Hz}, \mathrm{H}-6), 7.34(1 \mathrm{H}, \mathrm{dd}, J=8.4,7.6 \mathrm{~Hz}, \mathrm{H}-7), 7.89(1 \mathrm{H}, \mathrm{dd}, J=8.4,1.2 \mathrm{~Hz}, \mathrm{H}-8), 5.04(1 \mathrm{H}$, d, $\left.J=7.7 \mathrm{~Hz}, \mathrm{H}-1^{\prime}\right), 3.63\left(1 \mathrm{H}, \mathrm{dd}, J=9.0,7.7 \mathrm{~Hz}, \mathrm{H}-2^{\prime}\right), 3.53\left(1 \mathrm{H}, \mathrm{dd}, J=9.0,8.8 \mathrm{~Hz}, \mathrm{H}-3^{\prime}\right), 3.45(1 \mathrm{H}$, m, H-4'), 3.44 (1H, m, H-5'), 3.73 (1H, dd, $J=11.8,5.8$ Hz, H-6'a), 3.89 (1H, br.d, $J=11.8$ Hz, H-6'b), $5.06\left(1 \mathrm{H}, \mathrm{d}, J=7.8 \mathrm{~Hz}, \mathrm{H}-1^{\prime \prime}\right), 3.58\left(1 \mathrm{H}, \mathrm{dd}, J=9.0,7.8 \mathrm{~Hz}, \mathrm{H}-2^{\prime \prime}\right), 3.50(1 \mathrm{H}, \mathrm{dd}, J=9.0,8.5 \mathrm{~Hz}$, H-3"), 3.43 (1H, m, H-4"), 3.46 (1H, m, H-5"), 3.74 (1H, dd, $J=12.4,5.2 \mathrm{~Hz}, \mathrm{H}-6$ "a), 3.94 (1H, dd, $J=12.4,1.8 \mathrm{~Hz}, \mathrm{H}-6 " \mathrm{~b}) .{ }^{13} \mathrm{C}-\mathrm{NMR}\left(\mathrm{CDCl}_{3}, 100 \mathrm{MHz}\right) \delta(\mathrm{ppm}): 150.9$ (C-1), $111.3(\mathrm{C}-2), 112.2(\mathrm{C}-3)$, 151.0 (C-4), 155.1 (C-5), 112.5 (C-6), 128.3 (C-7), 114.8 (C-8), 130.4 (C-9), 117.5 (C-10), 103.0 (C-1'), $75.0\left(\mathrm{C}-2^{\prime}\right), 78.5\left(\mathrm{C}-3^{\prime}\right), 71.4\left(\mathrm{C}-4^{\prime}\right), 78.5\left(\mathrm{C}-5^{\prime}\right), 62.4$ (C-6'), $105.4\left(\mathrm{C}-1^{\prime \prime}\right), 75.0\left(\mathrm{C}-2^{\prime \prime}\right), 78.4\left(\mathrm{C}-3^{\prime \prime}\right)$, $71.4\left(\mathrm{C}-4^{\prime \prime}\right), 78.9\left(\mathrm{C}-5^{\prime \prime}\right), 62.5\left(\mathrm{C}-6^{\prime \prime}\right)$.

1,4,5-Trihydroxynaphthalene-1,5-di-O- $\beta$-D-glucopyranoside (16). Yellow amorphous powder, ${ }^{1} \mathrm{H}-\mathrm{NMR}$ $\left(\mathrm{CD}_{3} \mathrm{OD}, 400 \mathrm{MHz}\right) \delta(\mathrm{ppm}): 7.20(1 \mathrm{H}, \mathrm{d}, J=8.2 \mathrm{~Hz}, \mathrm{H}-2), 6.72(1 \mathrm{H}, \mathrm{d}, J=8.2 \mathrm{~Hz}, \mathrm{H}-3), 7.41$ (1H, dd, $J=7.8,1.6 \mathrm{~Hz}, \mathrm{H}-6), 7.36(1 \mathrm{H}, \mathrm{dd}, J=8.0,7.8 \mathrm{~Hz}, \mathrm{H}-7), 8.13(1 \mathrm{H}, \mathrm{dd}, J=8.0,1.6 \mathrm{~Hz}, \mathrm{H}-8), 4.92(1 \mathrm{H}$, 
d, $\left.J=7.8 \mathrm{~Hz}, \mathrm{H}-1^{\prime}\right), 3.60$ (1H, dd, $\left.J=8.7,7.9 \mathrm{~Hz}, \mathrm{H}-2^{\prime}\right), 3.49$ (1H, m, H-3'), 3.45 (1H, m, H-4'), 3.42 $\left(1 \mathrm{H}, \mathrm{m}, \mathrm{H}-5^{\prime}\right), 3.70\left(1 \mathrm{H}, \mathrm{dd}, J=12.2,5.1 \mathrm{~Hz}, \mathrm{H}-6^{\prime} \mathrm{a}\right), 3.88\left(1 \mathrm{H}, \mathrm{dd}, J=12.2,2.0 \mathrm{~Hz}, \mathrm{H}-6^{\prime} \mathrm{b}\right), 5.11(1 \mathrm{H}$, d, $\left.J=7.9 \mathrm{~Hz}, \mathrm{H}-1^{\prime \prime}\right), 3.58$ (1H, dd, $\left.J=9.2,7.9 \mathrm{~Hz}, 2^{\prime \prime}\right), 3.50$ (1H, m, H-3"), 3.43 (1H, m H-4"), 3.52 $(1 \mathrm{H}, \mathrm{m}, \mathrm{H}-5 "), 3.76$ (1H, dd, $J=12.2,5.8 \mathrm{~Hz}, \mathrm{H}-6$ "a), 3.97 (1H, dd, $J=12.2,2.1 \mathrm{~Hz}, \mathrm{H}-6 " \mathrm{~b}) .{ }^{13} \mathrm{C}-\mathrm{NMR}$ $\left(\mathrm{CDCl}_{3}, 100 \mathrm{MHz}\right) \delta(\mathrm{ppm}): 147.4(\mathrm{C}-1), 114.0$ (C-2), 110.9 (C-3), 150.6 (C-4), 155.8 (C-5), 112.7 (C-6), 126.6 (C-7), 119.4 (C-8), 130.2 (C-9), 117.3 (C-10), 104.0 (C-1'), 75.2 (C-2'), 78.2 (C-3'), 71.5 (C-4'), $78.3\left(\mathrm{C}-5^{\prime}\right), 62.4\left(\mathrm{C}-6^{\prime}\right), 104.6\left(\mathrm{C}-1^{\prime \prime}\right), 75.2\left(\mathrm{C}-2^{\prime \prime}\right), 78.3$ (C-3"), $71.5\left(\mathrm{C}-4^{\prime \prime}\right), 78.8$ (C-5"), $62.4\left(\mathrm{C}-6^{\prime \prime}\right)$.

1,4,8-Trihydroxynaphthalene-1-O- $\beta$-D-glucopyranoside (17). Yellow amorphous powder, ${ }^{1} \mathrm{H}-\mathrm{NMR}$ $\left(\mathrm{CD}_{3} \mathrm{OD}, 400 \mathrm{MHz}\right) \delta(\mathrm{ppm}): 6.70(1 \mathrm{H}, \mathrm{d}, J=8.6 \mathrm{~Hz}, \mathrm{H}-2), 7.22(1 \mathrm{H}, \mathrm{d}, J=8.6 \mathrm{~Hz}, \mathrm{H}-3), 6.81(1 \mathrm{H}, \mathrm{dd}$, $J=7.7,1.1 \mathrm{~Hz}, \mathrm{H}-6), 7.26(1 \mathrm{H}, \mathrm{dd}, J=8.8,7.7 \mathrm{~Hz}, \mathrm{H}-7), 7.64(1 \mathrm{H}, \mathrm{dd}, J=8.8,1.1 \mathrm{~Hz}, \mathrm{H}-8), 4.98(1 \mathrm{H}$, d, $\left.J=7.8 \mathrm{~Hz}, \mathrm{H}-1^{\prime}\right), 3.53$ (1H, dd, $\left.J=9.0,7.8 \mathrm{~Hz}, \mathrm{H}-2^{\prime}\right), 3.49$ (1H, m, H-3'), 3.42 (1H, m, H-4'), 3.49 $\left(1 \mathrm{H}, \mathrm{m}, \mathrm{H}-5^{\prime}\right), 3.74\left(1 \mathrm{H}, \mathrm{dd}, J=12.0,5.8 \mathrm{~Hz}, \mathrm{H}-66^{\prime}\right), 3.94\left(1 \mathrm{H}, \mathrm{dd}, J=12.0,2.1 \mathrm{~Hz}, \mathrm{H}-6^{\prime}\right) .{ }^{13} \mathrm{C}-\mathrm{NMR}$ $\left(\mathrm{CDCl}_{3}, 100 \mathrm{MHz}\right) \delta(\mathrm{ppm}): 150.8$ (C-1), 108.5 (C-2), 113.2 (C-3), 148.8 (C-4), 154.9 (C-5), 112.6 (C-6), 127.1 (C-7), 114.7 (C-8), 129.2 (C-9), 117.9 (C-10), 105.2 (C-1'), 75.2 (C-2'), 78.3 (C-3'), 71.6 (C-4'), $78.8\left(\mathrm{C}-5^{\prime}\right), 62.8\left(\mathrm{C}-6^{\prime}\right)$.

1,4,8-Trihydroxy-3-naphthalenecarboxylic acid-1-O- $\beta$-D-glucopyranoside ethyl ester (18). red powder, $\operatorname{mp} 136-138^{\circ} \mathrm{C} ;[\alpha]_{\mathrm{D}}^{25}-12.3$ ( $\left.c 0.50, \mathrm{MeOH}\right) ; \mathrm{UV} \lambda_{\max }=243 \mathrm{~nm}$; IR (KBr)vmax 3401, 2956, 1646, $1506 \mathrm{~cm}^{-1}$; ${ }^{1} \mathrm{H}-\mathrm{NMR}$ and ${ }^{13} \mathrm{C}-\mathrm{NMR}$ data see Table 1; HR-ESI-MS (positive): $\mathrm{m} / z$ 433.1375 [M $\left.+\mathrm{Na}\right]^{+}$(calcd for $\left.\mathrm{C}_{19} \mathrm{H}_{22} \mathrm{NaO}_{10}, 433.1381\right)$.

1,4,8-Trihydroxynaphthalene-1-O- $\beta$-D-[6'-O-(3",4",5"-trihydroxybenzoyl)] glucopyranoside (19). Yellow amorphous powder, ${ }^{1} \mathrm{H}-\mathrm{NMR}\left(\mathrm{CD}_{3} \mathrm{OD}, 400 \mathrm{MHz}\right) \delta(\mathrm{ppm}): 6.50(1 \mathrm{H}, \mathrm{d}, J=8.4 \mathrm{~Hz}, \mathrm{H}-2), 7.18(1 \mathrm{H}, \mathrm{d}$, $J=8.4 \mathrm{~Hz}, \mathrm{H}-3), 7.68(1 \mathrm{H}, \mathrm{dd}, J=8.0,3.1 \mathrm{~Hz}, \mathrm{H}-5), 7.23(1 \mathrm{H}, \mathrm{dd}, J=8.0,7.8 \mathrm{~Hz}, \mathrm{H}-6), 6.80$ (1H, dd, $J=8.2,3.1 \mathrm{~Hz}, \mathrm{H}-7), 4.96\left(1 \mathrm{H}, \mathrm{d}, J=7.8 \mathrm{~Hz}, \mathrm{H}-1^{\prime}\right), 3.58\left(1 \mathrm{H}, \mathrm{m}, \mathrm{H}-2^{\prime}\right), 3.53\left(1 \mathrm{H}, \mathrm{m}, \mathrm{H}-3^{\prime}\right), 3.29(1 \mathrm{H}$, m, H-4'), $3.84\left(1 \mathrm{H}, \mathrm{m}, \mathrm{H}-5^{\prime}\right), 4.53\left(1 \mathrm{H}, \mathrm{dd}, J=12.0,6.9 \mathrm{~Hz}, \mathrm{H}-6^{\prime} \mathrm{a}\right), 4.66$ (1H, dd, $J=12.0,2.1 \mathrm{~Hz}$, H-6'b), 7.18 (2H, s, H-2", H-6"). ${ }^{13} \mathrm{C}-\mathrm{NMR}\left(\mathrm{CDCl}_{3}, 100 \mathrm{MHz}\right) \delta(\mathrm{ppm}): 148.8$ (C-1), 108.6 (C-2), 113.3 (C-3), 150.7 (C-4), 114.7 (C-5), 127.1 (C-6), 112.2 (C-7), 154.8 (C-8), 117.9 (C-9), 128.9 (C-10), $105.4\left(\mathrm{C}-1^{\prime}\right), 78.2\left(\mathrm{C}-2^{\prime}\right), 75.1\left(\mathrm{C}-3^{\prime}\right), 72.0\left(\mathrm{C}-4^{\prime}\right), 76.2$ (C-5'), 65.1 (C-6'), $168.6\left(\mathrm{C}-7^{\prime \prime}\right), 121.6\left(\mathrm{C}-1^{\prime \prime}\right)$, 110.4 (C-2", C-6"), 146.7 (C-3", C-5"), 140.3 (C-4").

(4S)-4-Hydroxy- $\alpha$-tetralone-4-O- $\beta$-D-glucopyranoside (20). White amorphous powder, ${ }^{1} \mathrm{H}-\mathrm{NMR}\left(\mathrm{CD}_{3} \mathrm{OD}\right.$, $400 \mathrm{MHz}) \delta(\mathrm{ppm}): 3.05(1 \mathrm{H}, \mathrm{ddd}, J=17.8,9.6,4.8 \mathrm{~Hz}, \mathrm{H}-2 \mathrm{a}), 2.62(1 \mathrm{H}, \mathrm{ddd}, J=17.8,6.8,4.8 \mathrm{~Hz}$, H-2b), 2.45 (1H, dddd, $J=13.2,9.6,4.8,3.4 \mathrm{~Hz}, \mathrm{H}-3 \mathrm{a}), 2.38$ (1H, dddd, $J=13.2,6.8,6.2,4.8 \mathrm{~Hz}$, $\mathrm{H}-3 \mathrm{~b}), 5.10(1 \mathrm{H}, \mathrm{dd}, J=6.2,3.4 \mathrm{~Hz}, \mathrm{H}-4), 7.71(1 \mathrm{H}, \mathrm{dd}, J=7.8,1.6 \mathrm{~Hz}, \mathrm{H}-5), 7.63(1 \mathrm{H}, \mathrm{td}, J=7.8$, $1.6 \mathrm{~Hz}, \mathrm{H}-6), 7.47$ (1H, td, $J=7.8,1.6 \mathrm{~Hz}, \mathrm{H}-7), 7.97(1 \mathrm{H}, \mathrm{dd}, J=7.8,1.6 \mathrm{~Hz}, \mathrm{H}-8), 4.38(1 \mathrm{H}, \mathrm{d}$, $\left.J=7.8 \mathrm{~Hz}, \mathrm{H}-1^{\prime}\right), 3.24\left(1 \mathrm{H}, \mathrm{dd}, J=8.5,7.8 \mathrm{~Hz}, \mathrm{H}-2^{\prime}\right), 3.32\left(1 \mathrm{H}, \mathrm{m}, \mathrm{H}-3^{\prime}\right), 3.31\left(1 \mathrm{H}, \mathrm{m}, \mathrm{H}-4^{\prime}\right), 3.32(1 \mathrm{H}$, m, H-5'), 3.71 (1H, dd, $J=11.8,5.3 \mathrm{~Hz}, \mathrm{H}-6$ 'a), 3.95 (1H, dd, $\left.J=11.8,1.0 \mathrm{~Hz}, \mathrm{H}-6{ }^{\prime} \mathrm{b}\right) .{ }^{13} \mathrm{C}-\mathrm{NMR}$ $\left(\mathrm{CD}_{3} \mathrm{OD}, 100 \mathrm{MHz}\right) \delta(\mathrm{ppm}): 200.2$ (C-1), 35.6 (C-2), 31.6 (C-3), 75.1 (C-4), 130.4 (C-5), 135.1 (C-6), 129.9 (C-7), 128.2 (C-8), 133.1 (C-9), 144.1 (C-10), 103.3 (C-1'), 75.4 (C-2'), 78.2 (C-3'), 71.9 (C-4'), $78.1\left(\mathrm{C}-5^{\prime}\right), 63.0\left(\mathrm{C}-6^{\prime}\right)$. 
(4S)-4,5-Dihydroxy- $\alpha$-tetralone-4-O- $\beta$-D-glucopyranoside (21). White amorphous powder, ${ }^{1} \mathrm{H}-\mathrm{NMR}$ $\left(\mathrm{CD}_{3} \mathrm{OD}, 400 \mathrm{MHz}\right) \delta(\mathrm{ppm}): 3.12(1 \mathrm{H}, \mathrm{ddd}, J=17.6,14.0,5.1 \mathrm{~Hz}, \mathrm{H}-2 \mathrm{a}), 2.49(1 \mathrm{H}, \mathrm{dt}, J=17.6$, $3.3 \mathrm{~Hz}, \mathrm{H}-2 \mathrm{~b}), 2.19$ (1H, tt, $J=14.0,3.3 \mathrm{~Hz}, \mathrm{H}-3 \mathrm{a}), 2.56$ (1H, ddt, $J=14.0,5.1,3.3 \mathrm{~Hz}, \mathrm{H}-3 \mathrm{~b}), 5.41$ $(1 \mathrm{H}, \mathrm{t}, J=3.3 \mathrm{~Hz}, \mathrm{H}-4), 7.12(1 \mathrm{H}, \mathrm{dd}, J=7.9,1.1 \mathrm{~Hz}, \mathrm{H}-6), 7.30(1 \mathrm{H}, \mathrm{t}, J=7.9 \mathrm{~Hz}, \mathrm{H}-7), 7.48(1 \mathrm{H}$, $\mathrm{dd}, J=7.9,1.1 \mathrm{~Hz}, \mathrm{H}-8), 4.62\left(1 \mathrm{H}, \mathrm{d}, J=7.8 \mathrm{~Hz}, \mathrm{H}-1^{\prime}\right), 3.19\left(1 \mathrm{H}, \mathrm{dd}, J=8.7,7.8 \mathrm{~Hz}, \mathrm{H}-2^{\prime}\right), 3.35(1 \mathrm{H}$, m, H-3'), 3.36 (1H, m, H-4'), 3.36 (1H, m, H-5'), 3.75 (1H, dd, $J=12.2,4.8$ Hz, H-6'a), 3.90 (1H, dd, $J=12.2,1.8 \mathrm{~Hz}, \mathrm{H}-6$ 'b). ${ }^{13} \mathrm{C}-\mathrm{NMR}\left(\mathrm{CD}_{3} \mathrm{OD}, 100 \mathrm{MHz}\right) \delta(\mathrm{ppm}): 201.2$ (C-1), 34.0 (C-2), $30.3(\mathrm{C}-3)$, 70.1 (C-4), 156.8 (C-5), 122.3 (C-6), 130.7 (C-7), 119.2 (C-8), 134.7 (C-9), 130.0 (C-10), 104.1 (C-1'), 75. $6\left(\mathrm{C}-2^{\prime}\right), 78.1\left(\mathrm{C}-3^{\prime}\right), 71.6\left(\mathrm{C}-4^{\prime}\right), 78.1\left(\mathrm{C}-5^{\prime}\right), 62.9\left(\mathrm{C}-6^{\prime}\right)$.

(4S)-4,6-Dihydroxy- $\alpha$-tetralone-4-O- $\beta$-D-glucopyranoside (22). white amorphous powder, ${ }^{1} \mathrm{H}-\mathrm{NMR}$ $\left(\mathrm{CD}_{3} \mathrm{OD}, 400 \mathrm{MHz}\right) \delta(\mathrm{ppm}): 2.97(1 \mathrm{H}, \mathrm{ddd}, J=17.7,9.7,5.1 \mathrm{~Hz}, \mathrm{H}-2 \mathrm{a}), 2.52(1 \mathrm{H}, \mathrm{ddd}, J=17.7,6.4$, $4.8 \mathrm{~Hz}, \mathrm{H}-2 \mathrm{~b}), 2.38$ (1H, dddd, $J=13.6,9.6,4.8,3.5 \mathrm{~Hz}, \mathrm{H}-3 \mathrm{a}), 2.30$ (1H, dddd, $J=13.6,6.4,6.2$, $5.1 \mathrm{~Hz}, \mathrm{H}-3 \mathrm{~b}), 5.02(1 \mathrm{H}, \mathrm{dd}, J=6.2,3.5 \mathrm{~Hz}, \mathrm{H}-4), 7.04(1 \mathrm{H}, \mathrm{d}, J=2.2 \mathrm{~Hz}, \mathrm{H}-5), 6.85(1 \mathrm{H}, \mathrm{dd}, J=8.4$, $2.2 \mathrm{~Hz}, \mathrm{H}-7), 7.88(1 \mathrm{H}, \mathrm{d}, J=8.4 \mathrm{~Hz}, \mathrm{H}-8), 4.38\left(1 \mathrm{H}, \mathrm{d}, J=7.8 \mathrm{~Hz}, \mathrm{H}-1^{\prime}\right), 3.26(1 \mathrm{H}, \mathrm{dd}, J=8.7$, $\left.7.8 \mathrm{~Hz}, \mathrm{H}-2^{\prime}\right), 3.33\left(1 \mathrm{H}, \mathrm{t}, J=8.7 \mathrm{~Hz}, \mathrm{H}-3^{\prime}\right), 3.30\left(1 \mathrm{H}, \mathrm{m}, \mathrm{H}-4^{\prime}\right), 3.28\left(1 \mathrm{H}, \mathrm{m}, \mathrm{H}-5^{\prime}\right), 3.70(1 \mathrm{H}, \mathrm{dd}$, $\left.J=11.9,5.8 \mathrm{~Hz}, \mathrm{H}-6{ }^{\prime} \mathrm{a}\right), 3.93$ (1H, dd, $\left.J=11.9,1.6 \mathrm{~Hz}, \mathrm{H}-6{ }^{\prime} \mathrm{b}\right) .{ }^{13} \mathrm{C}-\mathrm{NMR}\left(\mathrm{CD}_{3} \mathrm{OD}, 100 \mathrm{MHz}\right) \delta(\mathrm{ppm})$ : 199.6 (C-1), 35.3 (C-2), 31.5 (C-3), 75.1 (C-4), 116.0 (C-5), 164.4 (C-6), 117.0 (C-7), 131.1 (C-8), 125.5 (C-9), 146.4 (C-10), 103.0 (C-1'), 75.3 (C-2'), 78.2 (C-3'), 71.9 (C-4'), 78.1 (C-5'), $63.2\left(\mathrm{C}^{\prime} 6^{\prime}\right)$.

(4S)-4,5,8-Trihydroxy- $\alpha$-tetralone-4-O- $\beta$-D-glucopyranoside (23). White amorphous powder, ${ }^{1} \mathrm{H}-\mathrm{NMR}$ $\left(\mathrm{CD}_{3} \mathrm{OD}, 400 \mathrm{MHz}\right) \delta(\mathrm{ppm}): 3.22(1 \mathrm{H}, \mathrm{ddd}, J=18.0,13.8,4.8 \mathrm{~Hz}, \mathrm{H}-2 \mathrm{a}), 2.52(1 \mathrm{H}, \mathrm{dt}, J=18.0$, $3.8 \mathrm{~Hz}, \mathrm{H}-2 \mathrm{~b}), 2.17$ (1H, tdd, $J=13.8,3.8,3.0 \mathrm{~Hz}, \mathrm{H}-3 \mathrm{a}), 2.48(1 \mathrm{H}, \mathrm{m}, \mathrm{H}-3 \mathrm{~b}), 5.40(1 \mathrm{H}, \mathrm{t}, J=3.0 \mathrm{~Hz}$, H-4), $7.11(1 \mathrm{H}, \mathrm{d}, J=9.1 \mathrm{~Hz}, \mathrm{H}-6), 6.81(1 \mathrm{H}, \mathrm{d}, J=9.1 \mathrm{~Hz}, \mathrm{H}-7), 4.52\left(1 \mathrm{H}, \mathrm{d}, J=7.8 \mathrm{~Hz}, \mathrm{H}-1^{\prime}\right), 3.17$ $\left(1 \mathrm{H}, \mathrm{dd}, J=8.9,7.8 \mathrm{~Hz}, \mathrm{H}-2^{\prime}\right), 3.32\left(1 \mathrm{H}, \mathrm{m}, \mathrm{H}-3^{\prime}\right), 3.32\left(1 \mathrm{H}, \mathrm{m}, \mathrm{H}-4^{\prime}\right), 3.32\left(1 \mathrm{H}, \mathrm{m}, \mathrm{H}-5^{\prime}\right), 3.72(1 \mathrm{H}$, dd, $J=12.1,4.8 \mathrm{~Hz}, \mathrm{H}-6$ 'a), $3.91\left(1 \mathrm{H}, \mathrm{dd}, J=12.1,1.8 \mathrm{~Hz}, \mathrm{H}-6{ }^{\prime} \mathrm{b}\right) .{ }^{13} \mathrm{C}-\mathrm{NMR}\left(\mathrm{CD}_{3} \mathrm{OD}, 100 \mathrm{MHz}\right) \delta$ (ppm): 207.2 (C-1), 34.3 (C-2), 29.9 (C-3), 69.3 (C-4), 148.6 (C-5), 127.0 (C-6), 119.6 (C-7), 157.3 (C-8), 116.9 (C-9), 127.5 (C-10), 103.4 (C-1'), 75.4 (C-2'), 78.2 (C-3'), 71.7 (C-4'), 78.1 (C-5'), 62.8 (C-6').

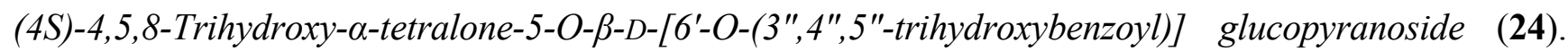
Light yellow amorphous powder, ${ }^{1} \mathrm{H}-\mathrm{NMR}\left(\mathrm{CD}_{3} \mathrm{OD}, 400 \mathrm{MHz}\right) \delta(\mathrm{ppm}): 2.49(1 \mathrm{H}, \mathrm{dd}, J=17.6,3.5 \mathrm{~Hz}$, H-2a), 3.03 (1H, ddd, $J=17.6,11.8,6.5 \mathrm{~Hz}, \mathrm{H}-2 \mathrm{~b}), 2.15$ (1H, m, H-3), 5.34 (1H, t, $J=3.2 \mathrm{~Hz}, \mathrm{H}-4)$, $7.42(1 \mathrm{H}, \mathrm{d}, J=9.2 \mathrm{~Hz}, \mathrm{H}-6), 6.76(1 \mathrm{H}, \mathrm{d}, J=9.2 \mathrm{~Hz}, \mathrm{H}-7), 4.78\left(1 \mathrm{H}, \mathrm{d}, J=7.7 \mathrm{~Hz}, \mathrm{H}-1^{\prime}\right), 3.55(1 \mathrm{H}, \mathrm{t}$, $\left.J=8.0 \mathrm{~Hz}, \mathrm{H}-2^{\prime}\right), 3.51\left(1 \mathrm{H}, \mathrm{m}, \mathrm{H}-3^{\prime}\right), 3.45\left(1 \mathrm{H}, \mathrm{m}, \mathrm{H}-4^{\prime}\right), 3.68\left(1 \mathrm{H}, \mathrm{td}, J=7.8,1.9 \mathrm{~Hz}, \mathrm{H}-5^{\prime}\right), 4.45(1 \mathrm{H}$, dd, $J=11.8,6.8 \mathrm{~Hz}, \mathrm{H}-6$ 'a), 4.55 (1H, dd, $\left.J=11.8,2.1 \mathrm{~Hz}, \mathrm{H}-6{ }^{\prime} \mathrm{b}\right), 7.07$ (2H, s, H-2", H-6"). ${ }^{13} \mathrm{C}-\mathrm{NMR}$ $\left(\mathrm{CD}_{3} \mathrm{OD}, 100 \mathrm{MHz}\right) \delta(\mathrm{ppm}): 206.2$ (C-1), 33.5 (C-2), 30.3 (C-3), 61.1 (C-4), 148.6 (C-5), 129.1 (C-6), 119.4 (C-7), 159.5 (C-8), 116.1 (C-9), 135.1 (C-10), 104.5 (C-1'), 75.3 (C-2'), 77.9 (C-3'), 71.7 (C-4'), 75.8 (C-5'), 64.6 (C-6'), 121.0 (C-1"), 110.4 (C-2"), 146.9 (C-3"), 140.4 (C-4"), 146.9 (C-5"), 110.3 (C-6"), $168.3\left(\mathrm{C}-7^{\prime \prime}\right)$.

(4S)-4-Hydroxy- $\alpha$-tetralone-4-O- $\beta$-D-(6'-O-4"-hydroxybenzoyl) glucopyranoside (25). yellow powder, $\mathrm{mp} 128-132{ }^{\circ} \mathrm{C} ;[\alpha]_{\mathrm{D}}^{25}-28.2(c 0.50, \mathrm{MeOH}) ; \mathrm{UV} \lambda_{\max }=262 \mathrm{~nm} ; \mathrm{CD}(\mathrm{MeOH}) \lambda_{\max }(\Delta \varepsilon): 236 \mathrm{~nm}(-12.6)$, 
$258 \mathrm{~nm}$ (+1.23). IR (KBr) $\nu_{\max } 3396,1728,1260,1180 \mathrm{~cm}^{-1} ;{ }^{1} \mathrm{H}-\mathrm{NMR}$ and ${ }^{13} \mathrm{C}-\mathrm{NMR}$ data see Table 1; HR-ESI-MS (positive): $m / z 445.0262[\mathrm{M}+\mathrm{H}]^{+}$(calcd for $\mathrm{C}_{23} \mathrm{H}_{25} \mathrm{O} 9,445.0267$ ).

(4S)-4,5-Dihydroxy- $\alpha$-tetralone-4-O- $\beta$-D-(6'-O-4"-hydroxybenzoyl) glucopyranoside (26). yellow powder, $\mathrm{mp} 132-135^{\circ} \mathrm{C} ;[\alpha]_{\mathrm{D}}^{25}-30.2(c 0.52, \mathrm{MeOH}) ; \mathrm{UV} \lambda_{\max }=274 \mathrm{~nm} ; \mathrm{CD}(\mathrm{MeOH}) \lambda_{\max }(\Delta \varepsilon): 234 \mathrm{~nm}(-8.60)$, $261 \mathrm{~nm}(+2.21)$. IR (KBr) $v_{\max } 3420,2960,1726,1255,1135 \mathrm{~cm}^{-1} ;{ }^{1} \mathrm{H}-\mathrm{NMR}$ and ${ }^{13} \mathrm{C}-\mathrm{NMR}$ data see Table 1; HR-ESI-MS (positive): $m / z$ 483.4276 [M + Na] ${ }^{+}$(calcd for $\mathrm{C}_{23} \mathrm{H}_{24} \mathrm{NaO}_{10}, 483.4279$ ).

(4S)-4,5,8-Thihydroxy- $\alpha$-tetralone-5-O- $\beta$-D-(6'-O-4"-hydroxybenzoyl) glucopyranoside (27). yellow powder, mp 145-148 ${ }^{\circ} \mathrm{C}$; $[\alpha]_{\mathrm{D}}^{25}-31.4(c 0.47, \mathrm{MeOH})$; UV $\lambda_{\max }=264 \mathrm{~nm} ; \mathrm{CD}(\mathrm{MeOH}) \lambda_{\max }(\Delta \varepsilon)$ : $241 \mathrm{~nm}$ (-9.46), $266 \mathrm{~nm}(+0.93), 271 \mathrm{~nm}(-0.55), 292 \mathrm{~nm}(+0.35)$. IR (KBr) $v_{\max }$ 3400, 2994, 1725, $1056 \mathrm{~cm}^{-1}$; HR-ESI-MS (positive): $m / z 477.1058[\mathrm{M}+\mathrm{H}]^{+}$(calcd for $\mathrm{C}_{23} \mathrm{H}_{25} \mathrm{O}_{11}, 477.1054$ ).

\subsection{Acid Hydrolysis and Sugar Analysis}

Compounds 18, 25-27 (1.5 mg) were refluxed with $1.0 \mathrm{~mol} / \mathrm{L} \mathrm{HCl}\left(5 \mathrm{~mL}\right.$, dioxane $\left./ \mathrm{H}_{2} \mathrm{O}, v / v\right)$ for $7 \mathrm{~h}$. After filtration, the acid aqueous layer was neutralized with $5 \% \mathrm{NaOH}$ and desalted with Sephadex LH-20 to obtain the sugar residue $(0.8 \mathrm{mg})$. The residues were dissolved in pyridine $(5 \mathrm{~mL})$ and 1-(trimetrylsilyl)-imidazole $(0.5 \mathrm{~mL})$ at $60{ }^{\circ} \mathrm{C}$ for $10 \mathrm{~min}$. The reaction mixtures were dried with a stream of $\mathrm{N}_{2}$, the residues were partitioned between $\mathrm{CHCl}_{2}$ and $\mathrm{H}_{2} \mathrm{O}$. The organic layers were analyzed by GC using an L-Chirasil-Val column $(0.32 \mathrm{~mm} \times 25 \mathrm{~m})$. Temperatures of injector and detector were maintained at $200{ }^{\circ} \mathrm{C}$. A temperature gradient system was used for the oven; the initial temperature remained at $100{ }^{\circ} \mathrm{C}$ for $1 \mathrm{~min}$ and then was raised to $180{ }^{\circ} \mathrm{C}$ at the rate of $5{ }^{\circ} \mathrm{C} / \mathrm{min}$. Peaks of the hydrolysate of 18 and 25-27 were respectively detected at $14.72 \mathrm{~min}, 14.72 \mathrm{~min}, 14.73 \mathrm{~min}, 14.72 \mathrm{~min}$. The final result was to compare the retention time of authentic sample of D-glucose (SigmaAldrich, St. Louis, MO, USA) treated in the same manner with 1-(trimetrylsilyl)-imidazole in pyridine which was detected at $14.72 \mathrm{~min}$. Thus, it was concluded that all the sugar moieties of $\mathbf{1 8}$ and 25-27 are D-glucose.

\subsection{Cytotoxicity Assays}

\subsubsection{Cell Culture}

The cytotoxicity of compounds 1-27 was performed against human liver carcinoma cells (HepG-2) by MTT assay [25,26]. HepG-2 cell line was maintained in DMEM supplemented with $10 \%$ fetal bovine serum (FBS), 100 units $/ \mathrm{mL}$ penicillin, and $100 \mu \mathrm{g} / \mathrm{mL}$ streptomycin (Gibco-BRL). The cells were incubated in $5 \% \mathrm{CO}_{2}$ humidified at $37^{\circ} \mathrm{C}$ for growth.

\subsubsection{Measurement of Cell Proliferation by MTT Assay}

HepG-2 cells in logarithmic growth phase were seeded in a 96-well microtiter plates and kept overnight for attachment. Twenty-seven compounds and positive control (cisplatin), dissolved in dimethyl sulfoxide, were diluted to various concentrations with Dulbecco's Modified Eagle Medium (DMEM) from 200 to $0.5 \mu \mathrm{M}$ for $24 \mathrm{~h}$. The optical density (OD) was measured at $570 \mathrm{~nm}$ using a 
multiscan microplate reader. All experiments were performed in triplicate. Data were expressed as the concentration required for inhibiting growth of HepG-2 by $50 \%$ (IC50).

\section{Conclusions}

Twenty-seven naphthoquinones and their derivatives, including four new naphthalenyl glucosides and twenty-three known compounds, have been isolated with the aim of exploring the relationship between cytotoxicity and structures. The results indicated that in naphthoquinones with 2,3-unsaturated moieties, the position of the substituents was at the aryl ring portion or the quinone ring portion of naphthoquinone played an important role in the cytotoxic activity. Moreover, the type of substituents also had an effect on the activity. And in general, when these compounds were substituted with the phenolic hydroxyl group, they had stronger activity against the HepG-2 cells. Napthoquinone glycosides had no activity or weaker activity. So far, we are not able to definitely confirm that the type of saccharide is an essential factor for cytotoxic activity, since compounds obtained are all substituted with glucose. These results will provide experimental bases for further structural modifications to yield better active derivatives.

\section{Acknowledgments}

This work was kindly supported by the National Science Foundation (grant NO.81202890), China Postdoctoral Science Foundation funded project (2013M530164/2014T70374), Heilongjiang Postdoctoral Fund (LBH-Z13195), Harbin city youth science and technology innovation talents (2013RFQXJ052).

\section{Author Contributions}

Yuanyuan Zhou, Bingyou Yang and Haixue Kuang came up with the conception of this experiment. Yuanyuan Zhou and Zhaoxi Liu wrote the manuscript. Yuxin Liu and Yanqiu Jiang carried out the experiments and analyzed the spectral data. Xiaoli Wang conducted the cytotoxicity assays against HepG-2 and deduced the preliminary structure-activity relationships for these naphthoquinones from green walnut husks of Juglans mandshurica Maxim. All authors had read and approved the final manuscript.

\section{Conflicts of Interest}

The authors declare no conflict of interest.

\section{References}

1. Lu, S.; Tian, J.; Sun, W.; Meng, J.; Wang, X.; Fu, X.; Wang, A.; Lai, D.; Liu, Y.; Zhou, L. Bis-naphtho-gamma-pyrones from fungi and their bioactivities. Molecules 2014, 19, 7169-7188.

2. Yao, D.L.; Zhang, C.H.; Luo, J.; Jin, M.; Zheng, M.S.; Cui, J.M.; Son, J.K.; Li, G. Chemical constituents from the leaves of Juglans mandshurica. Arch. Pharm. Res. 2015, 38, 480-484.

3. Lin, H.; Zhang, Y.W.; Hua, Y.; Bao, Y.L.; Wu, Y.; Sun, L.G.; Yu, C.L.; Huang, Y.X.; Wang, E.B.; Jiang, H.Y.; et al. Three new compounds from the stem bark of Juglans mandshurica. J. Asian Nat. Prod. Res. 2014, 16, 819-824. 
4. Kim, S.H.; Lee, K.S.; Son, J.K.; Je, G.H.; Lee, J.S.; Lee, C.H.; Cheng, C.J. Cytotoxic Compounds from the Roots of Juglans mandshurica. J. Nat. Prod. 1998, 61, 643-645.

5. Bai, W.N.; Liao, W.J.; Zhang, D.Y. Nuclear and chloroplast DNA phylogeography reveal two refuge areas with asymmetrical gene flow in a temperate walnut tree from East Asia. New Phytol. 2010, 188, 892-901.

6. Zhang, Y.L.; Cui, Y.Q.; Zhu, J.Y.; Li, H.Z.; Mao, J.W.; Jin, X.B.; Wang, X.S.; Du, Y.F.; Lu, J.Z. The anti-tumor effect and biological activities of the extract JMM6 from the stem-barks of the Chinese Juglans mandshurica Maxim on human hepatoma cell line bel-7402. Afr. J. Tradit. Complement. Altern. Med. 2013, 10, 258-269.

7. Park, G.; Oh, M.S. Inhibitory effects of Juglans mandshurica leaf on allergic dermatitis-like skin lesions-induced by 2, 4-dinitrochlorobenzene in mice. Exp. Toxicol. Pathol. 2014, 66, 97-101.

8. Park, G.H.; Jang, D.S.; Oh, M.S. Juglans mandshurica leaf extract protects skin fibroblasts from damage by regulating the oxidative defense system. Biochem. Biophys. Res. Commun. 2012, 421, 343-348.

9. Negi, A.S.; Luqman, S.; Srivastava, S.; Krishna, V.; Gupta, N.; Darokar, M.P. Antiproliferative and antioxidant activities of Juglans regia fruit extracts. Pharm. Biol. 2011, 49, 669-673.

10. D'Arcy Doherty, M.; Rodgers, A.; Cohen, G.M. Mechanisms of toxicity of 2-and 5-hydroxy-1,4naphthoquinone; absence of a role for redox cycling in the toxicity of 2-hydroxy-1,4-naphthoquinone to isolated hepatocytes. J. Appl. Toxicol. 1987, 7, 123-129.

11. Xu, H.L.; Yu, X.F.; Qu, S.C.; Sui, D.Y. Juglone, isolated from Juglans mandshurica Maxim, induces apoptosis via down-regulation of AR expression in human prostate cancer LNCaP cells. Bioorg. Med. Chem. Lett. 2013, 23, 3631-3634.

12. Machida, K.; Matsuoka, E.; Kasahara, T.; Kikuchi, M. Studies on the constituents of Juglans Species. I. structural determination of (4S)- and (4R)-4-hydroxy- $\alpha$-tetralone derivatives from the fruit of Juglans mandshurica Maxim var. sieboldiana MAKINO. Chem. Pharm. Bull. 2005, 53, 934-937.

13. Chen, G.; Pi, X.M.; Yu, C.Y. A new naphthalenone isolated from the green walnut husks of Juglans mandshurica Maxim. Nat. Prod. Res. 2015, 29, 174-179.

14. Li, J.; Sun, J.X.; Yu, H.Y.; Chen, Z.Y.; Zhao, X.Y.; Ruan, H.L. Diarylheptanoids from the root bark of Juglans cathayensis. Chin. Chem. Lett. 2013, 24, 521-523.

15. Yang, H.J.; Cho, H.J.; Sim, S.H.; Chung, Y.K.; Kim, D.D.; Sung, S.H.; Kim, J.; Kim, Y.C. Cytotoxic terpenoids from Juglans sinensis leaves and twigs. Bioorg. Med. Chem. Lett. 2012, 22, 2079-2083.

16. Machida, K.; Yogiashi, Y.; Matsuda, S.; Suzuki, A.; Kikuchi, M. A new phenolic glycoside syringate from the bark of Juglans mandshurica Maxim var. sieboldiana MAKINO. J. Nat. Med. 2009, 63, 220-222.

17. Wellington, K.W. Understanding cancer and the anticancer activities of naphthoquinones-A review. RSC Adv. 2015, 5, 20309-20338.

18. Liu, L.J.; Li, W.; Kazuo, K.; Zhang, S.J.; Tamotsu, N. New $\alpha$-Tetralonyl Glucosides from the Fruit of Juglans mandshurica. Chem. Pharm. Bull. 2004, 52, 566-569. 
19. Min, B.S.; Nakamura, N.; Miyashiro, H.; Kim, Y.H.; Hattori, M. Inhibition of human immunodeficiency virus type 1 reverse transcriptase and ribonuclease $\mathrm{H}$ activities by constituents of Juglans mandshurica. Chem. Pharm. Bull. 2000, 48, 194-200.

20. Noureini, S.K.; Wink, M. Antiproliferative effect of the isoquinoline alkaloid papaverine in hepatocarcinoma HepG-2 cells-Inhibition of telomerase and induction of senescence. Molecules 2014, 19, 11846-11849.

21. Noureini, S.K.; Wink, M. Dose-dependent cytotoxic effects of boldine in HepG-2 cells- telomerase inhibition and apoptosis induction. Molecules 2015, 20, 3730-3743.

22. Yu, H.Y.; Zhang, X.Q.; Li, X.; Zeng, F.B.; Ruan, H.L. 2-methoxyjuglone induces apoptosis in HepG-2 human hepatocellular carcinoma cells and exhibits in vivo antitumor activity in a $\mathrm{H} 22$ mouse hepatocellular carcinoma model. J. Nat. Prod. 2013, 76, 889-895.

23. Raquel, C.M.; Ana, J.A.; Maria, T.M.; José, D.B.M.F.; Danilo, D.R.; Eulogio, L.M.; Marília, O.F.G.; Bento, E.S.; Ana, P.N.N.A.; Cláudia, P.; et al. Cytotoxic activity of naphthoquinones with special emphasis on juglone and its 5-O-methyl derivative. Chem. Biol. Interact. 2010, 184, 439-448.

24. Liu, L.J.; Qi, F.Q.; Gong, X.F. Studies on the cytotoxicity of naphthoquinone derivatives from the fresh rejvenated fruits of Juglans mandshurica. Chin. JMAP 2010, 27, 574-577.

25. Mosmann, T. Rapid colorimetric assay for cellular growth and survival: Application to proliferation and cytotoxicity assays. J. Immunol. Methods 1983, 65, 55-63.

26. Carmichael, J.; DeGraff, W.G.; Gazdar, A.F.; Minna, J.D.; Mitchell, J.B. Evaluation of a tetrazolium-based semiautomated colorimetric assay: Assessment of chemosensitivity testing. Cancer Res. 1987, 47, 936-942.

Sample Availability: Samples of the compounds 1-27 are available from the authors.

(C) 2015 by the authors; licensee MDPI, Basel, Switzerland. This article is an open access article distributed under the terms and conditions of the Creative Commons Attribution license (http://creativecommons.org/licenses/by/4.0/). 